\title{
FE Model of Low Grade Rubber for Modeling Housing's Low-Cost Rubber Base Isolators
}

\author{
Hidajat Sugihardjo ${ }^{a^{*}}$ Tavio $^{\mathrm{b}}$, Yudha Lesmana ${ }^{\mathrm{c}}$ \\ ${ }^{a}$ Associate Professor, Department of Civil Engineering, Institut Teknologi Sepuluh Nopember (ITS), Kampus ITS Sukolilo, Surabaya 60111, Indonesia. \\ ${ }^{b}$ Professor, Department of Civil Engineering, Institut Teknologi Sepuluh Nopember (ITS), Kampus ITS Sukolilo, Surabaya 60111, Indonesia. \\ ${ }^{c}$ PhD Candidate, Department of Civil Engineering, Institut Teknologi Sepuluh Nopember (ITS), Kampus ITS Sukolilo, Surabaya 60111, Indonesia.
}

Received 23 December 2017; Accepted 30 January 2018

\begin{abstract}
An accurate selection of strain energy function (SEF) plays a very important role for predicting the actual behavior of rubber material in the finite element analysis (FEA). The common method for selecting the SEF is by using the curve fitting procedure. However, the behavior of some typical rubbers, such as low grade rubbers (average hardness value of 47.2), cannot be predicted well by only using the curve fitting procedure. To accurately predict the actual behavior of such specifically nearly incompressible material, a series of FEA were carried out to simulate the actual behavior of four physical testing materials, namely the uniaxial, the planar shear, the equibiaxial, and the volumetric tests. This FEA is intended to examine the most suitable constitutive model in representing the rubber characteristics and behavior. From the comparisons, it can be concluded that the Ogden model provides a reasonably accurate prediction compared to the remaining investigated constitutive material models. Finally, the appropriate SEF, i.e. the Ogden model, was adopted for modeling a low-cost rubber base isolator (LCRBI) in the finite element analysis (FEA). The simple uniaxial compression test of the LCRBI is required for validating that the selected SEF works for predicting the actual behavior of LCRBI.
\end{abstract}

Keywords: Constitutive Model; Finite Element Analysis; Hyperelastic Material; Low Grade Rubber; Strain Energy Function; Curve Fitting.

\section{Introduction}

Hyperelastic material, such as rubber, has been applied in various kinds of industrial products such as seals, vehicles tires, hydraulic hoses, shock absorbers, vibration isolators or dampers, and others [1-10]. Generally, this material undergoes very large strain and performs highly nonlinear in stress-strain relationship. The characteristic of hyperelastic material has confirmed its unique behavior through a series experimental testing and describes its actual behavior through a proper selection of constitutive model [11-12]. The highly demand of rubber material in various applications, has required a good understanding for the engineers regarding the unique behavior of rubber material. Because of the complicated rubber characteristic, a critical issue in the nonlinear elastic theory is to apply the elastic law on the hyperelastic material, which is the primary goal in developing the powerful analysis tools [13].

Commonly, rubbers are considered as hyperelastic material that performs a highly-nonlinear large deformation. A number of constitutive models are available in many literatures to describe the actual rubber behavior by comparing one model to another. However, the critical issue in nonlinear hyperelastic material is how to determine the rubber parameters that govern the constitutive equations of hyperelastic material. Typically, three experimental tests must be conducted to define the rubber parameters for constitutive model. They involve the uniaxial tensile, planar shear, and

* Corresponding author: hidajat.sugihardjo@gmail.com

\footnotetext{
doi http://dx.doi.org/10.28991/cej-030966

$>$ This is an open access article under the CC-BY license (https://creativecommons.org/licenses/by/4.0/).

(C) Authors retain all copyrights.
} 
equibiaxial tensile tests. In application, the parameters of constitutive model are different from one test to another. At least, three sets of experimental test data has to be found in order to obtain the accurate rubber parameters. The assumption of homogeneity of kinematic fields from each test is used to develop the approach. Furthermore, each homogeneous test has different sample geometry [14].

In order to represent the characteristic of rubber material, various geometrical and physical nonlinearities must be considered. Up to present, the finite element method (FEM) is a very powerful tool for analyzing the rubber characteristic and behavior. In the past, this type of materials cannot be defined analytically because of their nonlinearities and complex geometries [15]. The critical point in modeling hyperelastic material is in the proper selection of the constitutive model. Most types of rubbers perform a unique behavior in term of stress-strain relationship, such as softening behavior under small deformation or strain and highly stiffening behavior when the deformation or strain increases. Nevertheless, number classical constitutive models of hyperelastic material perform undesired results by giving inappropriate prediction of actual rubber behavior in the overall range of deformation or strain. Some constitutive models are able to predict the actual rubber behavior but only in the restricted deformation state or under certain deformation or strain. Only a few of them can simulate well up to strain magnitudes of 600-700 percent. Even though number of models can be considered quite accurate under certain deformation or strain state, but many failed in the prediction at other states [16-17].

In the finite element analysis (FEA), hyperelastic material is typically described using one of the available hyperelasticity models, such as the Mooney-Rivlin, Yeoh, Ogden, Neo-Hookean, and others. The detailed characteristics of hyperelastic material depend on the measured physical behavior and theoretical consideration. The general characteristics of these material models always involve several material constants in their formula obtained from the experimental data. Based on the experimental data, the parameters are fitted with the test data for certain required range of deformation or strain. In some cases, it is sometimes found that the models can represent very well the test data for particular ranges of strain or deformation yet only predict inaccurately for other ranges [18].

In order to accurately model incompressible material, such as rubber, in the FEA, the experimental data are required to best represent the actual rubber characteristics. Three types of experimental tests are typically carried out on rubber, namely the uniaxial tensile, the planar shear, and the equibiaxial tensile tests [19]. The stress-strain relationships obtained from the tests are used to obtain the specific material parameters for deriving the proper strain energy function (SEF).

The selection of a suitable SEF of rubber material depends on its application, corresponding parameters, and available material test data [20]. Several criteria are found in previous researches to define the proper SEF of rubber material, i.e. the stress-strain curve of the material should perform the entire ' $S$ ' shape response, the change of deformation mode should be applicable under uniaxial tension, simple planar shear, and equibiaxial tension, the number of constitutive parameters should be small to minimize the need of experimental tests for their determination, and the mathematical equation should be simple to develop the possible numerical application of the model [21-23].

For specific implementation of rubber material, slight changes in its chemical composition can considerably influence its mechanical properties. Thus, it is important to experimentally test a specific rubber and then employ it through FEA to obtain an appropriate SEF. Then, the selected SEF can be further employed to simulate the assembly, such LCRBI, in which the specific rubber is utilized. Among the available commercial softwares, ANSYS provides a number of SEFs to accommodate the nonlinear characteristics and behavior of hyperelastic materials such as rubber. The verification of SEFs using FEA with various available softwares for different rubbers against the experimental data can be found in literatures [19, 23-27]. The distinctine results were found by Hosseinzadeh et al. [27]. From the investigation, it was concluded that the exponential- exponential and general exponential-power law models have a good agreement with the experimental data in modeling the nonlinear elastic behavior of demineralized and deproteinized bovine cortical femur bone compared to the Mooney-Rivlin and Ogden models

To achieve the objective of the study that is to propose an appropriate SEF for a specifically given rubber, a series of laboratory tests was carried out, comprising the uniaxial tensile, the planar shear, the equibiaxial tensile, and the volumetric tests, and to obtain the complete stress-strain relationships. Normally, a simple curve fitting process is sufficient as the first step to determine the most suitable SEF for a particular rubber as hyperelastic material. In the study, five hyperelastic models were selected for curve fitting. However, it was found that none of the employed models could perform well to closely match the experimental data. In the case, further rigorous analytical approach is required, i.e. the FEA to ensure which hyperelastic model can best fit the experimental data, and thus, the most suitable SEF can be decided to represent particular rubber material for more complex applications in the FE program, such as LCRBI.

This paper presents an approach method and technique to determine a proper SEF for rubber by using the FEA based on the laboratory test data and the research works of [19, 23]. Compressive test of a low-cost rubber base isolator (LCRBI) was also performed in the study for validating the selected constitutive model. The appropriateness 
of the selected SEF from the rubber material was then verified further by modeling the LCRBI through the FEA. Since the results showed a reasonably good agreement with the experimental data, the FE approach can be proposed as one of the alternative solutions among other available techniques in selecting the appropriate SEF of hyperelastic materials, particularly the studied low-grade rubber material for LCRBI.

\section{Basic Theory: Constitutive Model}

The constitutive behavior of a nearly incompressible hyperelastic material is basically obtained from the strain energy density function, SEF (W), which is the contribution of the isochoric elastic part, $W_{\text {iso, }}$, and the volumetric elastic part, $W_{v o l}$, as follows [12];

$W=W_{\text {iso }}\left(I_{1}, I_{2}, I_{3}\right)+W_{v o l}\left(J_{e l}\right)$

Where $\mathrm{W}$ is strain per unit reference volume, and $\mathrm{I}_{1}, \mathrm{I}_{2}$, and $\mathrm{I}_{3}$ are three invariants of Green deformation tensor which can be determined in terms of principal stretch ratios and given by;

$$
\begin{aligned}
& I_{1}=\lambda_{1}^{2}+\lambda_{2}^{2}+\lambda_{3}^{2} \\
& I_{2}=\lambda_{1}^{2} \lambda_{2}^{2}+\lambda_{2}^{2} \lambda_{3}^{2}+\lambda_{3}^{2} \lambda_{1}^{2} \\
& I_{3}=\lambda_{1}^{2} \lambda_{2}^{2} \lambda_{3}^{2}
\end{aligned}
$$

Where $\lambda_{1}, \lambda_{2}$, and $\lambda_{3}$ are the three elongation ratios; $\lambda_{\mathrm{i}}=\varepsilon_{\mathrm{i}}+1 ; J_{e l}$ is the elastic volume ratio.

Five constitutive models of nearly incompressible material exploited in the study are described briefly in the following sections.

\subsection{Neo-Hookean Model}

The Neo-Hookean model is the simplest form among polynomial models. It is best suited for 20 to 30 percent strain and its SEF is presented as [28];

$$
W=C_{10}\left(I_{1}-3\right)+\frac{1}{D_{1}}\left(J_{e l}-1\right)^{2}
$$

Where $C_{10}=\mu_{0} / 2, \mu_{0}$ is the initial shear modulus, $D_{1}$ is the material constant that introduces compressibility.

The accuracy of the Neo-Hookean model is quite consistent with that of the Mooney-Rivlin model. Both models are only well-performed when the material undergoes small strains. This model is offered only in terms of the first deviatoric invariant [29].

\subsection{Mooney-Rivlin Model}

The Mooney-Rivlin model is the simplest model of the complete polynomial models. Its SEF is given as follows [30-31];

$$
W=C_{10}\left(I_{1}-3\right)+C_{01}\left(I_{2}-3\right)+\frac{1}{D_{1}}\left(J_{e l}-1\right)^{2}
$$

The model matches for a small or intermediate strain (100 percent tensile strain; 30 percent compressive strain). The most favorite ones of constitutive models are the Mooney-Rivlin and the Ogden models. The disadvantage is that the material parameters (not physically-based) must be obtained by experiments. The fitting procedure can be complicated if the number of parameters is large [32].

\subsection{Yeoh Model}

A reduced polynomial model is formed after the revision by a higher order term of $I_{1}$ applying on the SEF of NeoHookean model as follows [33-34]:

$$
W=\sum_{i=1}^{N} C_{10}\left(I_{1}-3\right)^{i}+\sum_{i=1}^{N} \frac{1}{D_{i}}\left(J_{e l}-3\right)^{2 i}
$$

When $N$ is 3 , the corresponding model becomes Yeoh model as follows;

$$
W=\sum_{i=1}^{3} C_{i 0}\left(I_{1}-3\right)^{i}+\sum_{i=1}^{3} \frac{1}{D_{i}}\left(J_{e l}-3\right)^{2 i}
$$

The initial shear modulus and bulk modulus are given by:

$$
\mu_{0}=2 C_{10}, K_{0}=\frac{2}{D_{1}}
$$


This model is applicable for a much wider range of deformation and able to predict the stress-strain behavior in different deformation modes from data gained in one simple deformation mode such as uniaxial extension [35].

\subsection{Ogden Model}

The Ogden model presents the SEF of rubber under finite deformation [36]. The principal stretches are measurable quantities and act as variables in Ogden model. The SEF of Ogden model is given by

$$
W=\sum_{i=1}^{N} \frac{2 \mu_{i}}{\alpha_{i}^{2}}\left(\lambda_{1}^{\alpha_{i}}+\lambda_{2}^{\alpha_{i}}+\lambda_{3}^{\alpha_{i}}-3\right)+\sum_{i=1}^{N} \frac{1}{D_{i}}\left(J_{e l}-1\right)^{2 i}
$$

Where $\lambda_{1}^{2} \lambda_{2}^{2} \lambda_{3}^{2}=1, I_{1}$ and $I_{2}$ determine the first part of the Ogden's SEF. However, $I_{1}$ and $I_{2}$ cannot fully represent the function. The simulated accuracy is dependent on the value of $N$. Then $N$ value results in the difficulty of fitting material constants. The Ogden model is suitable for large strain up to 700 percent.

\subsection{Arruda-Boyce Model}

The Arruda-Boyce model can be applied for the strain up to 300 percent. The strain energy is presented as [37]

$$
W=\mu_{0} \sum_{i=1}^{5} \frac{C_{i}}{\lambda_{m}^{i-2}}\left(I_{1}^{i}-3\right)+\frac{1}{D}\left[\frac{J_{e l}^{2}-1}{2}-\ln \left(J_{e l}\right)\right]
$$

Where $C_{1}=1 / 2, C_{2}=1 / 20, C_{3}=11 / 1050, C_{4}=19 / 7000, C_{5}=519 / 673,750$, and $\lambda_{m}$ is the locking stretch at which upturn of stress-strain curve would rise significantly [38].

\section{Materials and Methods}

In this section, the analytical method for determining hyperelastic material parameters and four types of experimental tests for hyperelastic materials, namely the uniaxial tensile, the planar shear, the equibiaxial tensile, and the volumetric tests, are presented. For each type of tests, three specimens were taken from the same rubber product, yet different batches. This is intended to investigate the uniformity of the product batches and to ensure that the product provides the representative test data

Although the material performs different stress-strain curves under different loading condition, a unique and appropriate SEF for specific rubber can still be selected which is applicable under all loading condition. In order to select the appropriate SEF, a number of experimental tests must be carried out, or at least one of these simple tests, namely the uniaxial tensile, planar shear, or equibiaxial, must be conducted [39]. Generally, the SEF can be expressed in the following form [40].

$$
W=\int_{1}^{\lambda} \frac{\sigma}{\lambda_{i}} \partial \lambda_{i}
$$

Where $\sigma$ is the engineering stress. Equation (10) can be developed for various loading conditions, such as the uniaxial tensile, the planar shear, the equibiaxial, and the volumetric tests.

The tests were utilized for the curve fitting process to obtain the low-grade rubber constants and to select its appropriate constitutive model. The requirement for the curve fitting process is a simple stress-strain function which is able to represent each loading condition expected in the experiments, namely the uniaxial tensile, the planar shear, the equibiaxial tensile, and the volumetric tests. The simple stress-strain relation can thus simply be applied in the FEA. Hence, a simple reversible loading condition was applied on the test specimen to capture the softening effect of particular low-grade rubber characteristic.

In the experimental tests, an Instron servo hydraulic or electromechanical test instruments were used to serve the loadings. Non-contacting strain measuring devices such as video and laser extensometer are required to measure the strains. It should be attached freely without any contact with the specimens.

The loading rate during the tests was set in a slow cyclic loading mode (SCLM) of about $0.01 \mathrm{~mm} / \mathrm{mm} / \mathrm{sec}$. In the SCLM, the specimens were stretched to a desired strain level and then unloaded at the same loading rate to a nearly zero stress condition.

The characteristic and behavior of hyperelastic material particularly rubber is quite unique. The structural properties of rubber changes significantly during the first several times of loadings as it strains. This means if the rubber is stretched to a certain strain level and then released back to a zero stress level for several times, the change in its structural properties (stress-strain relationship) decreases from cycle to cycle and diminishes. This phenomenon is commonly known as the Mullin's effect [33]. In some condition, when the stress-strain relationship of the rubber does not exhibit significant change anymore, the rubber material can be considered to be stable for the strain level below 
that particular maximum strain. However, if the rubber is then loaded up to a new higher maximum strain level, the structural properties will change again considerably.

Prior to all the low-grade rubber material tests elaborated in the subsequent sections at Axel Product, Inc., Ann Arbor, Michigan, USA, five hardness tests were conducted earlier in the Laboratory of Innovative Engineering Materials, Department of Material and Metalurgy Engineering, Institut Teknologi Sepuluh Nopember (ITS), Surabaya, Indonesia. The tests were carried out in accordance with ASTM D2240 using a special apparatus called Durometer Shore A. From the tests, it was found that the hardness values of the low grade rubbers were 46, 46, 48, 48, and 48 with an average value of 47.2 .

\subsection{Uniaxial Tensile Test}

The important requirement of the the test is to achieve a state of pure tensile strain that the specimen must be longer in the direction of elongation than its width and thickness. The stress-strain relationship of the uniaxial tensile test could be idealized as shown in Figure 1. The laser strain measuring device was attached freely without any contact with the specimen (see Figure 1).

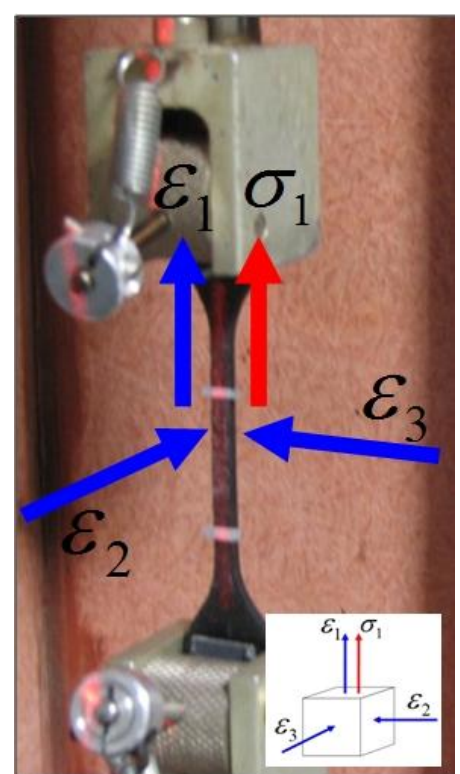

Figure 1. Idealized stress-strain state of uniaxial tensile test

For isotropic material, the principal stretches of uniaxial tension can be expressed as [41];

$\lambda_{1}=\lambda ; \lambda_{2}=\lambda_{3}=\frac{1}{\sqrt{\lambda}}$

And the corresponding stress of uniaxial tension test could be expressed by:

$\sigma_{1}=\sigma=\lambda \frac{\partial W(\lambda)}{\partial \lambda}, \sigma_{2}=\sigma_{3}=0$

Where $W(\lambda)=W\left(\lambda, \lambda^{-0.5}, \lambda^{-0.5}\right)$

As can be seen in Figure 1, the red arrow, $\sigma_{1}$, describes the tensile stress that deforms the specimen to the strain level $\varepsilon_{1}$, where $\sigma_{1}$ and $\varepsilon_{1}$ are the stress and strain in stretching direction, respectively. The stresses (red) or strain (blue) where no arrow is shown in Figure 1. are zero.

The test was performed on the dogbone-shaped specimens with an effective gage length of $50 \mathrm{~mm}$ shown in Figure 2. All the specimens were stretched up to a maximum displacement of approximately $50 \mathrm{~mm}$ (100 percent of the effective gage length). Each level consists of four cycles. The loading history of the test and its corresponding hysteretic curve are shown in Figures 3 and 4, respectively. 

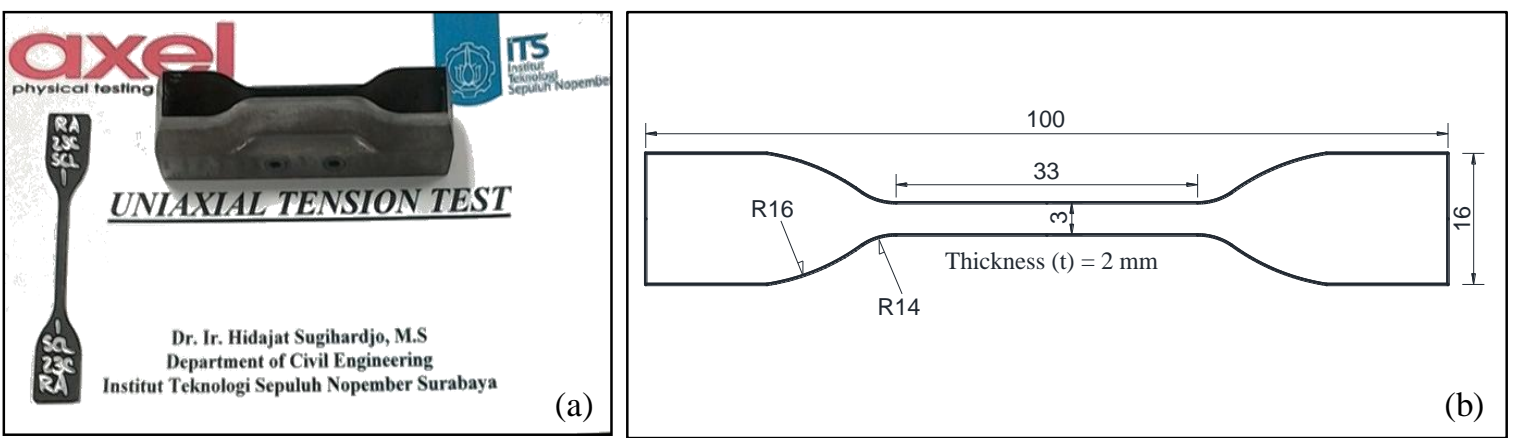

Figure 2. A dogbone-shaped specimen for uniaxial tensile test; (a). Test specimen label; (b). Schematic of test specimen

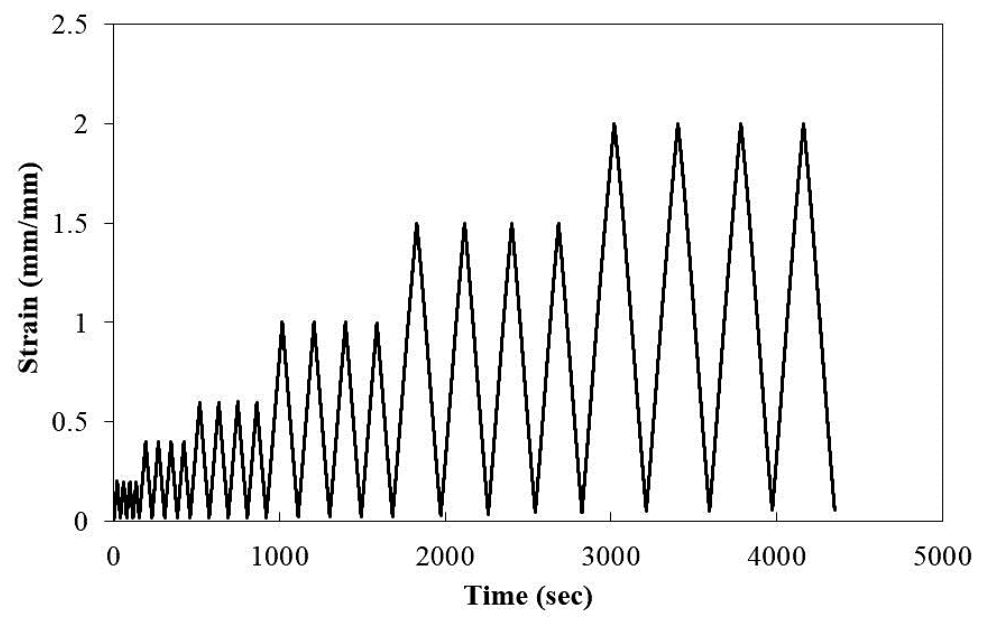

Figure 3. Loading history of uniaxial tensile test

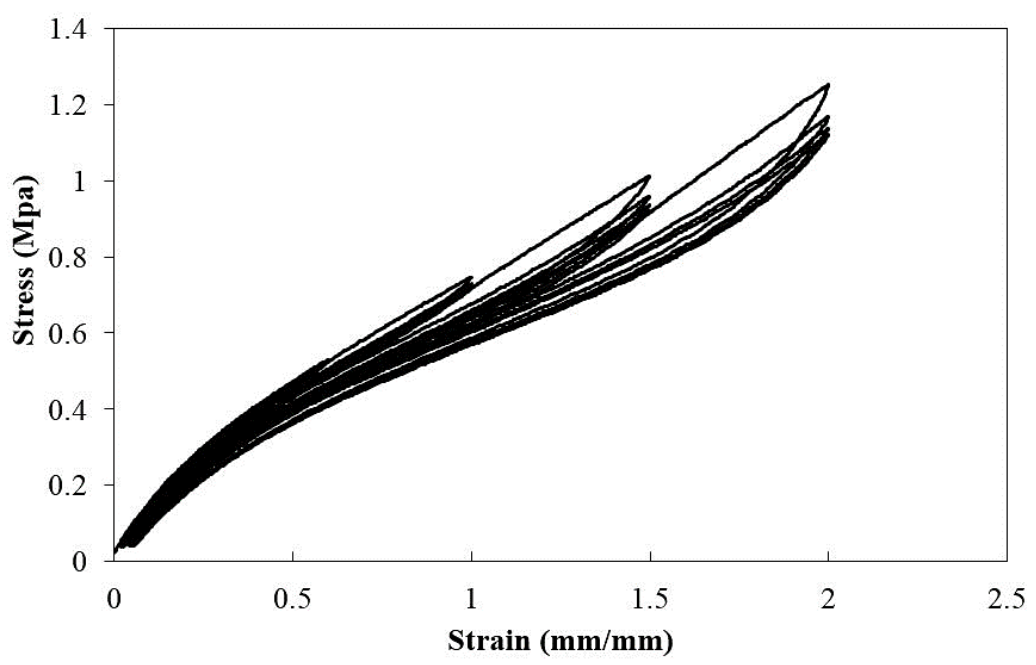

Figure 4. Hysteretic curve of uniaxial tensile test

\subsection{Planar Shear Test}

In planar shear test, the significant requirement of the specimen is that its dimension in the loading direction must be much shorter than its width. The primary goal is to create a laboratory test where the specimen is perfectly constrained in the lateral direction such that the specimen thinning occurs in the thickness direction only. Thus, it describes the actual shear behavior of the rubber. The stress-strain state for planar shear test could be idealized as shown in Figure 5. The laser extensometer are required to measure the strains (see Figure 5).

For isotropic material, the principal stretches of planar shear can be expressed as [41].

$\lambda_{1}=\lambda ; \lambda_{2}=\lambda^{-1} ; \lambda_{3}=1$

And the principal stress are as follow 


$$
\sigma_{1}=\sigma=\lambda \frac{\partial W(\lambda)}{\partial \lambda}, \sigma_{2}=0
$$

Where $W(\lambda)=W\left(\lambda, \lambda^{-1}, 1\right)$.

Similar to the uniaxial tensile test, the red arrow, $\sigma_{1}$, describes the tensile stress that deforms the specimen to the strain level $\varepsilon_{1}$, where $\sigma_{1}$ and $\varepsilon_{1}$ are the stress and strain in loading direction, respectively. The stress $\sigma_{3}$ and no strain $\varepsilon_{3}$ illustrate that the specimen is constrained perfectly in the lateral direction, thus it only experiences deformation in the thickness direction during the test. The stresses (red) or strains (blue) where no arrow is shown in Figure 5. are zero.

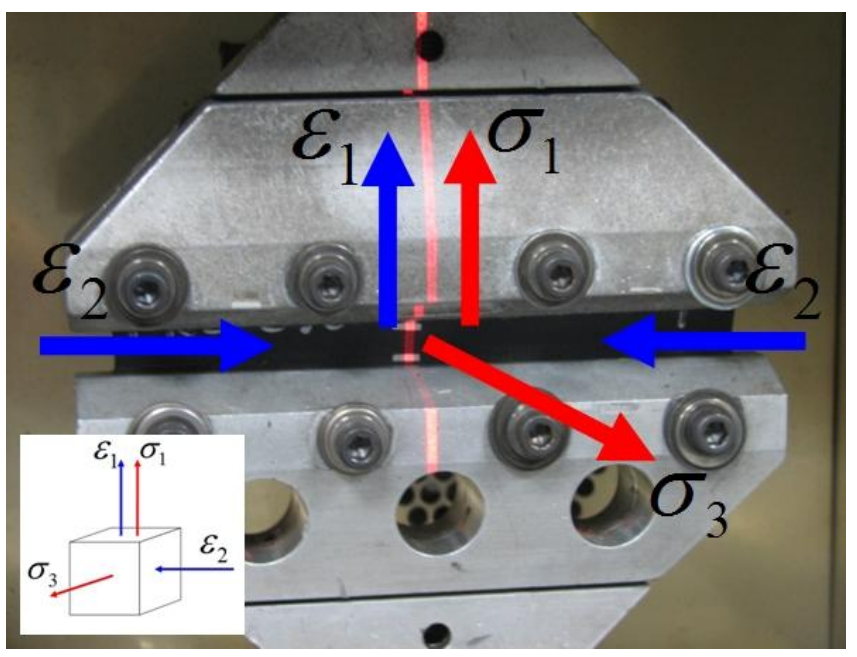

Figure 5. Idealized stress-strain state of planar shear test

The width of specimen must be at least ten times than its length in the stretching or loading direction (see Figure 6). The specimens were cut from the rubber sheets to have the dimensions of $150 \mathrm{~mm}$ by $15 \mathrm{~mm}$.
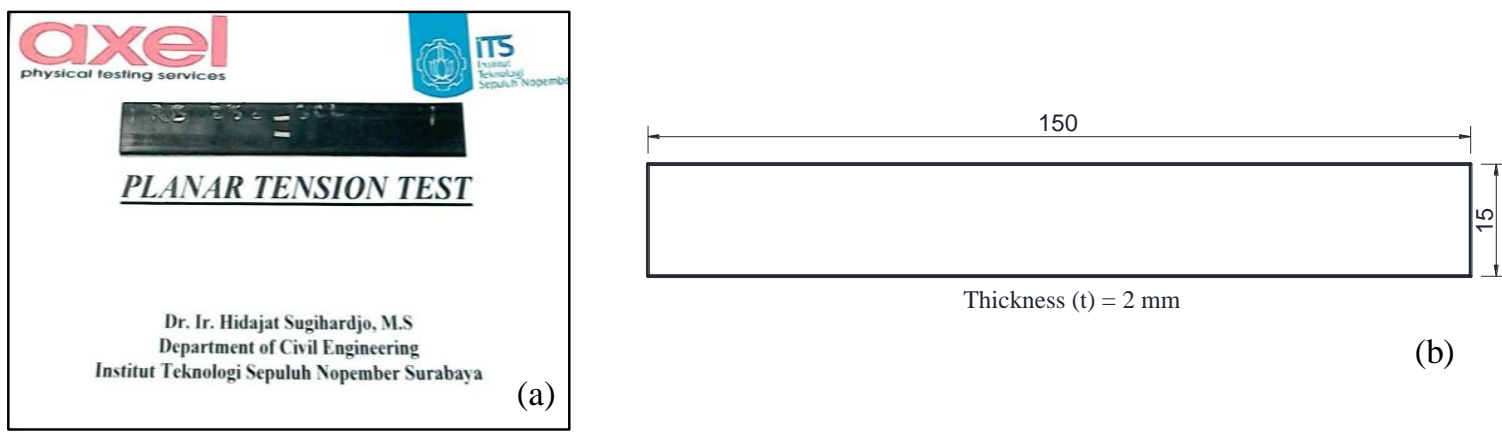

(a)

(b)

Figure 6. One of the specimens for planar shear test; (a). Test specimen label; (b). Schematic of test specimen

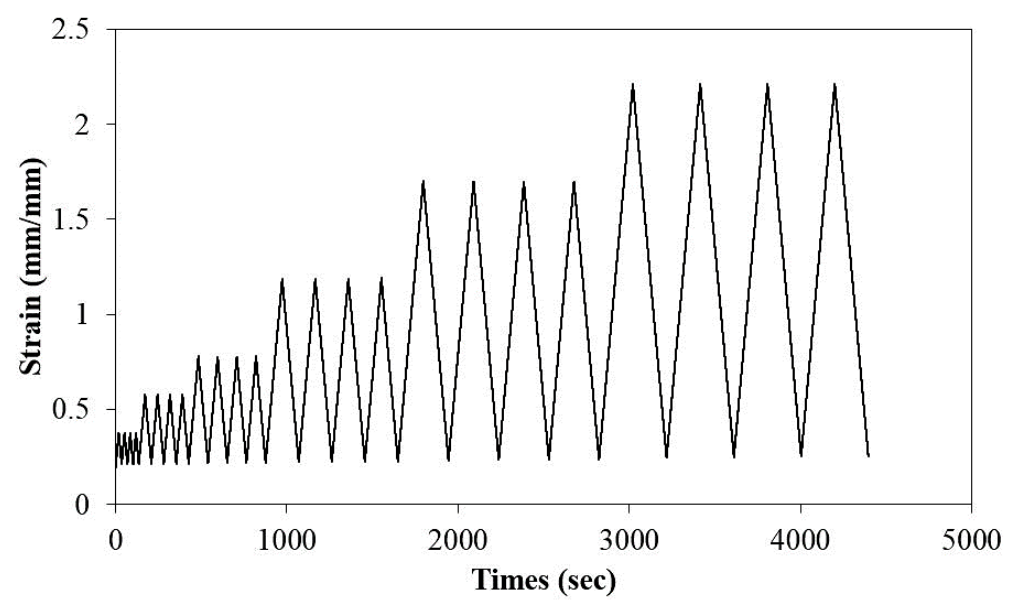

Figure 7. Loading history of planar shear test 


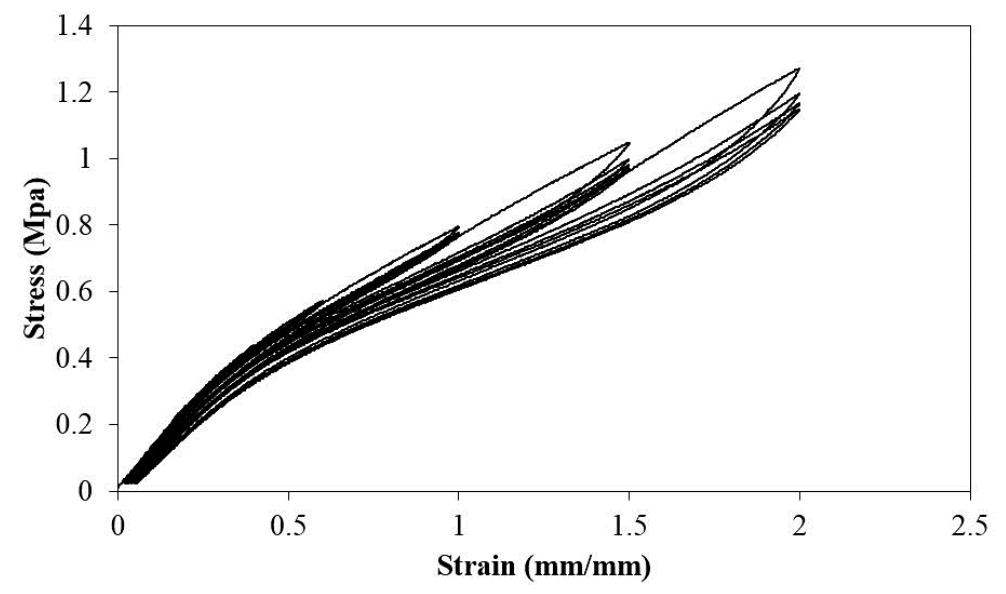

Figure 8. Hysteretic curve of planar shear test

All the specimens were stretched up to a maximum displacement of approximately $15 \mathrm{~mm}$ (100 percent of the effective gage length). The loading history of the test and its hysteretic curve are given in Figures $7 \& 8$, respectively.

\subsection{Equibiaxial Tensile Test}

For equibiaxial tensile test, both the specimen and loading condition are created to ensure the radially-directional deformation equivalent with pure compression. The equibiaxial strain can be performed by stretching the circular disk in radial direction to certain strain level. The stress-strain state of the equibiaxial tensile test is illustrated in Figure 9.

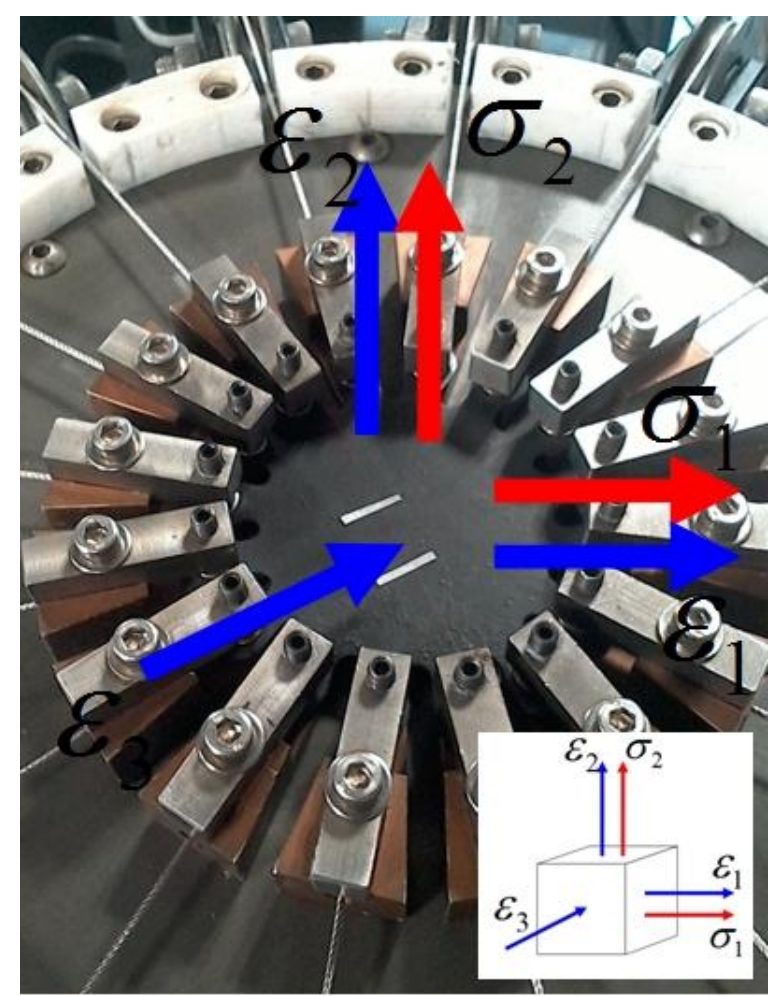

Figure 9. Idealized stress-strain state of equibiaxial tensile test

In this state, the principal strain can be expressed as follows [41]:

$\lambda_{1}=\lambda_{2}=\lambda$

And the principal stresses can be calculated by

$\sigma_{1}=\sigma_{2}=\lambda \frac{1}{2} \frac{\partial W(\lambda)}{\partial \lambda}, \sigma_{3}=0$

Where $W(\lambda)=W\left(\lambda, \lambda, \lambda^{-2}\right)$.

Similarly, in Figure 9, the red arrows, $\sigma_{1}$ and $\sigma_{2}$ describe the tensile stresses that deform the specimen in radial 
direction to the strain levels $\varepsilon_{1}$ and $\varepsilon_{2}$ in loading direction, where $\sigma_{1}$ and $\sigma_{2}$ are stresses in radial direction and $\varepsilon_{1}, \varepsilon_{2}$, and $\varepsilon_{3}$ are the strain condition equivalent to simple pure compression. The stresses (red) or strains (blue) where no arrow is shown in Figure 9 are zero.
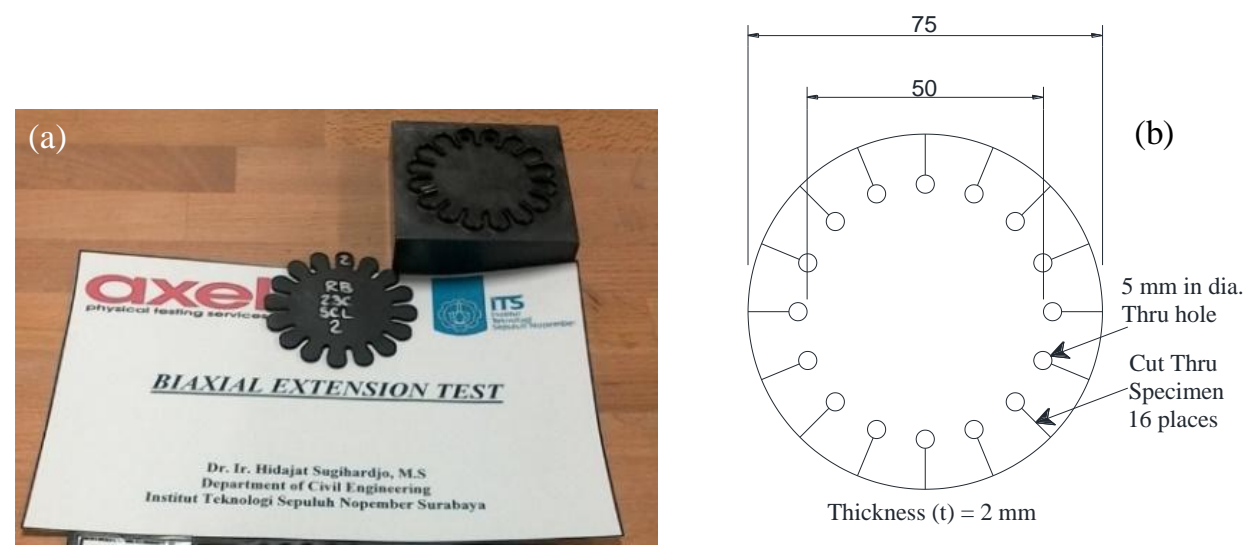

Figure 10. One of the specimen for equibiaxial tensile test; (a). Test specimen label; (b). Schematic of test specimen

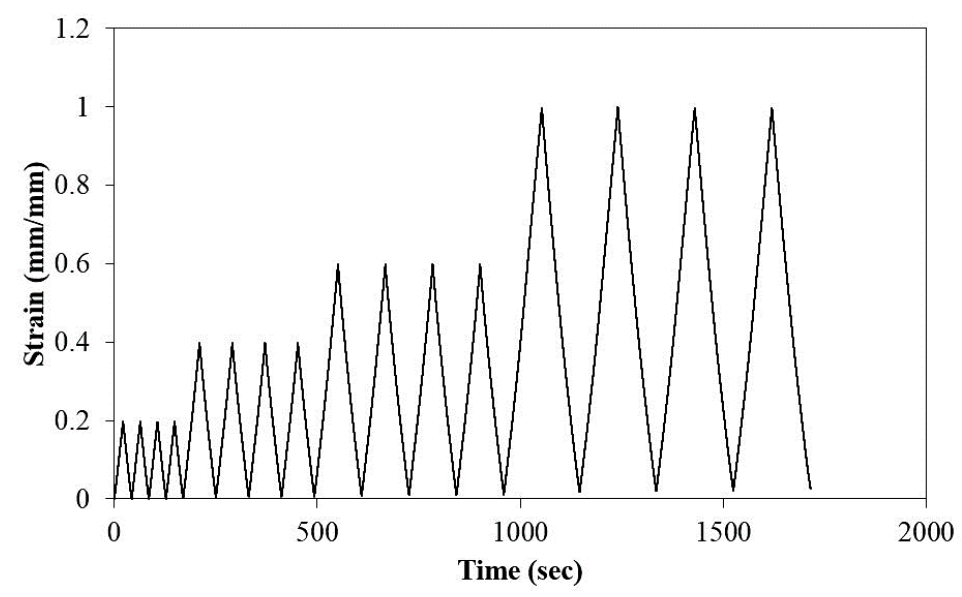

Figure 11. Loading history of equibiaxial tensile test

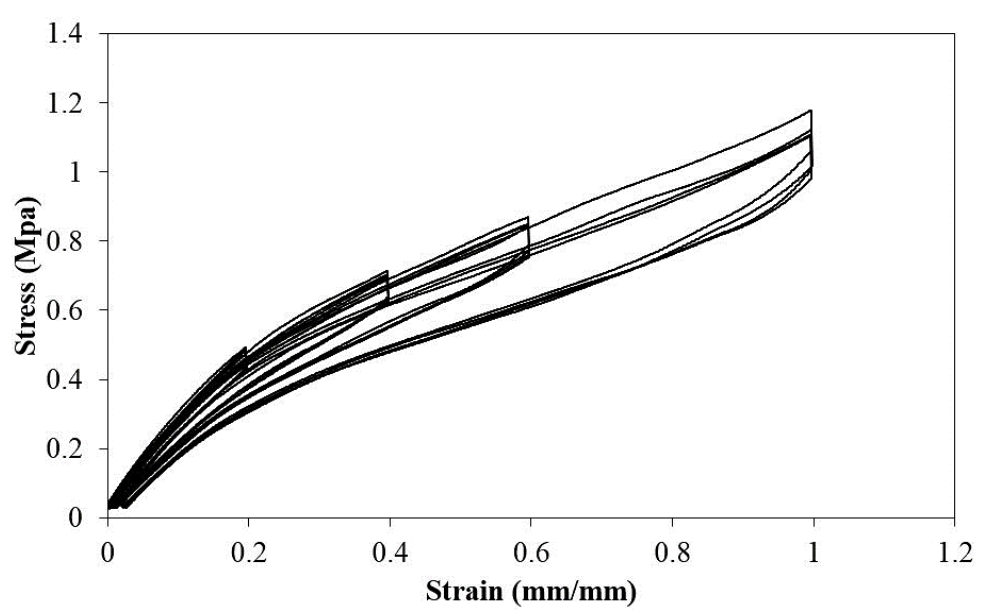

Figure 12. Hysteretic curve of equibiaxial tensile test

The test specimens were cut from the rubber sheets to have a diameter of $75 \mathrm{~mm}$ with an effective area within 50$\mathrm{mm}$ diameter as shown in Figure 10. The effective gage length of specimen is set to be $25 \mathrm{~mm}$ in radial direction. Figures 11 and 12. show the loading history of the test and its hysteretic curve, respectively.

\subsection{Volumetric Test}

In the volumetric test, a cylindrical specimen is constrained in the fixture and compressed uniaxially. The displacement occurred during the test is very small. The basic assumption of rubber behavior during the test is similar to a fluid regarding the equal reaction force in all direction. The very small volume change during the test under 
hydrostatic pressure $(p)$ characterizes the rubber material as a nearly incompressible material. The stress-strain state for the volumetric test can be expressed in Eqs. 17 and 18 and idealized as shown in Figure 13. The red arrows, $\sigma_{1}, \sigma_{2}$, and $\sigma_{3}$, represent the hydrostatic pressures that deform the specimen to the strain levels $\varepsilon_{1}, \varepsilon_{2}$, and $\varepsilon_{3}$ in all directions. The stresses (red) or strains (blue) where no arrow is shown in Figure13. are zero. The volumetric ratio is given by [41].

$$
\begin{aligned}
& \lambda_{1}=\lambda_{2}=\lambda_{3}=J_{e l}^{1 / 3} \leq 1 \\
& \sigma_{1}=\sigma_{2}=\sigma_{3}=\frac{\partial W}{\partial J_{e l}}=-p
\end{aligned}
$$

Where $\sigma_{1}, \sigma_{2}$, and $\sigma_{3}$ are the hydrostatic pressures and the strains $\varepsilon_{1}, \varepsilon_{2}$, and $\varepsilon_{3}$ are all constrained in a very stiff fixture.

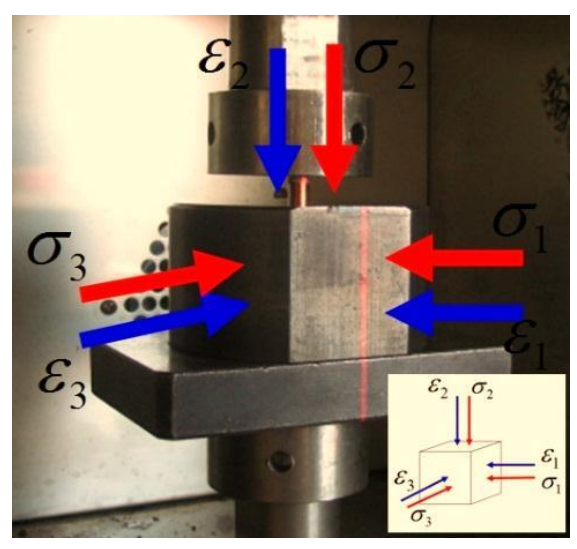

Figure 13. Idealized stress-strain state of volumetric test

The test specimens were cut from the rubber sheets. They had a diameter of $6.35 \mathrm{~mm}$. Typically, five circular disks with $2 \mathrm{~mm}$ thick each, to form a total thickness of $10 \mathrm{~mm}$, were stacked as shown in Figure 14. The axial load in the vertical direction is applied with the displacement control to a particular displacement of approximately $1 \mathrm{~mm}$ with a loading rate of about $0.01 \mathrm{~mm} / \mathrm{mm} / \mathrm{sec}$ as can be seen in Figure 15. Figure 16. shows the hysteretic curve of the volumetric test.
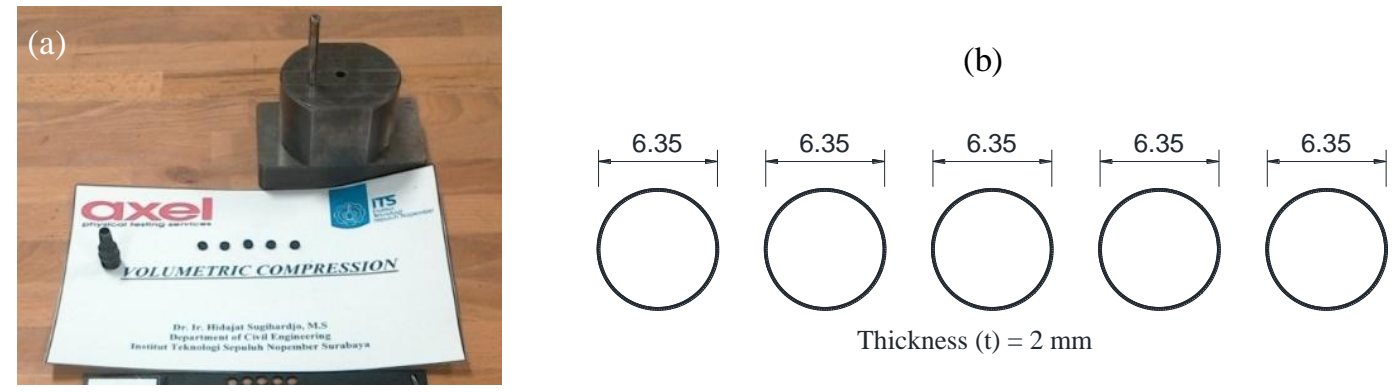

Thickness $(\mathrm{t})=2 \mathrm{~mm}$

Figure 14. One of the specimens for volumetric test; (a). Test specimen label; (b). Schematic of test specimen

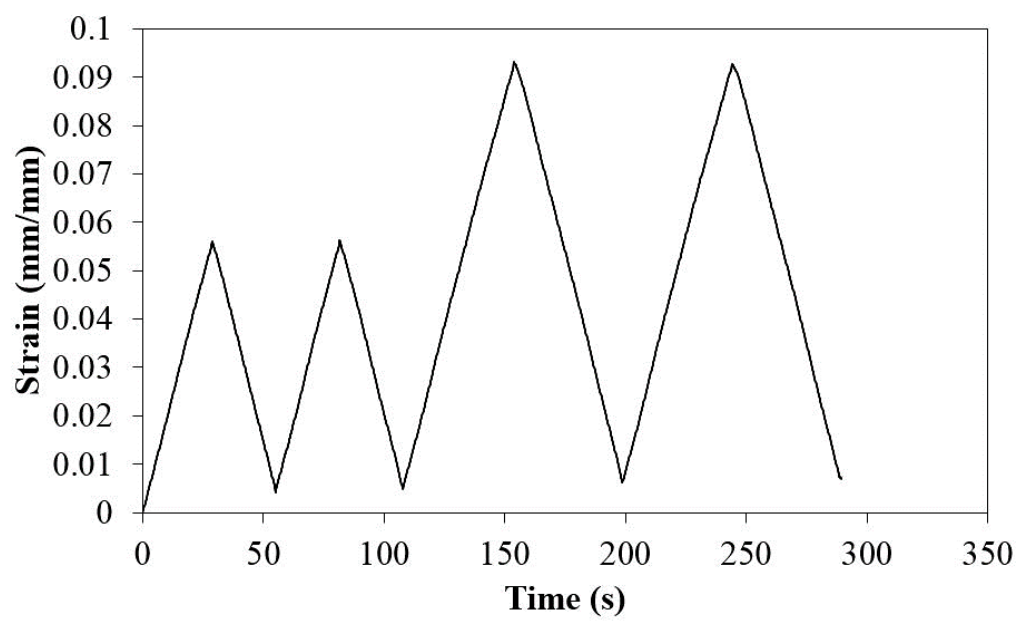

Figure 15. Loading history of volumetric test 


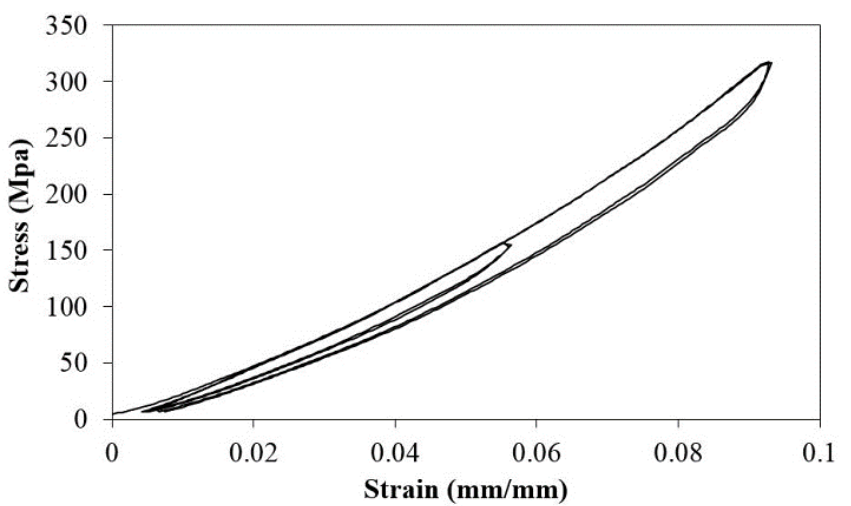

Figure 16. Hysteretic curve of volumetric test

\section{Curve Fitting Process}

In order to select the most suitable hyperelastic model, ANSYS provide the curve fitting feature. This feature considerably simplifies the user's effort by only comparing several available models with experimental data; the most suitable model can be decided. The experimental stress-strain data is required to determine the appropriate coefficients of SEF during curve fitting process. The test data required for curve fitting process is the uniaxial tensile, planar shear, equibiaxial, and volumetric tests which generates an equation for SEF in terms of strain invariants or stretches of hyperlastic material. The analytical stress-strain data was generated by Eqs. 12, 14, 16, and 18, and the models were evaluated using Eqs. 3 to 9 to fit the experimental data as shown in Figures 17 to 21. The most stable experimental data from all cycles for each test was selected for the curve fitting process [19]. The stress-strain data pairs from the uniaxial tensile, the planar shear, and the equibiaxial tensile tests are used to determine the shear constants Cij, whereas the compressibility constant, $\mathrm{Di}$, is determined by the volumetric test. For each stress-strain data pairs, the ANSYS yields the coefficients of SEF for all five hyperelastic listed in Table 1.

Among the three experimental test data, only the uniaxial tensile and planar shear test data are able to match the curves generated by all the selected models from the ANSYS. However, this is not the case of the equibiaxial data test. In Figure 17, the Neo-Hokean model exhibits it is more suitable for use for predict the uniaxial tensile and planar shear test data. Curve fitting for the equibiaxial test indicates that its accuracy is a major problem, thus, it cannot be used to represent the rubber material behavior in FEA. Similar condition is also found for the Yeoh and Arruda-Boyce models shown in Figures. 19 and 21, respectively. All these models provide a reasonably good prediction for both uniaxial tensile and planar shear tests, but exhibit insufficient prediction for the equibiaxial test.

Among the available models, it was found that only Ogden and Mooney-Rivlin appeared to be the most suitable models for predicting the SEF of the specifically low grade rubber as shown in Figures 2 and 4. It can be seen from the figure that the curves exhibit similar pattern with the experimental data. However, their capability to closely match the experimental data still cannot be considered sufficient for accurately predicting the actual low-grade rubber behavior. In the case, further rigorous analytical approach is required, i.e. the FEA to ensure which hyperelastic model can best fit the experimental data, and thus, the most suitable SEF can be decided to represent particular rubber material for more complex applications in the FE program, such as LCRBI.

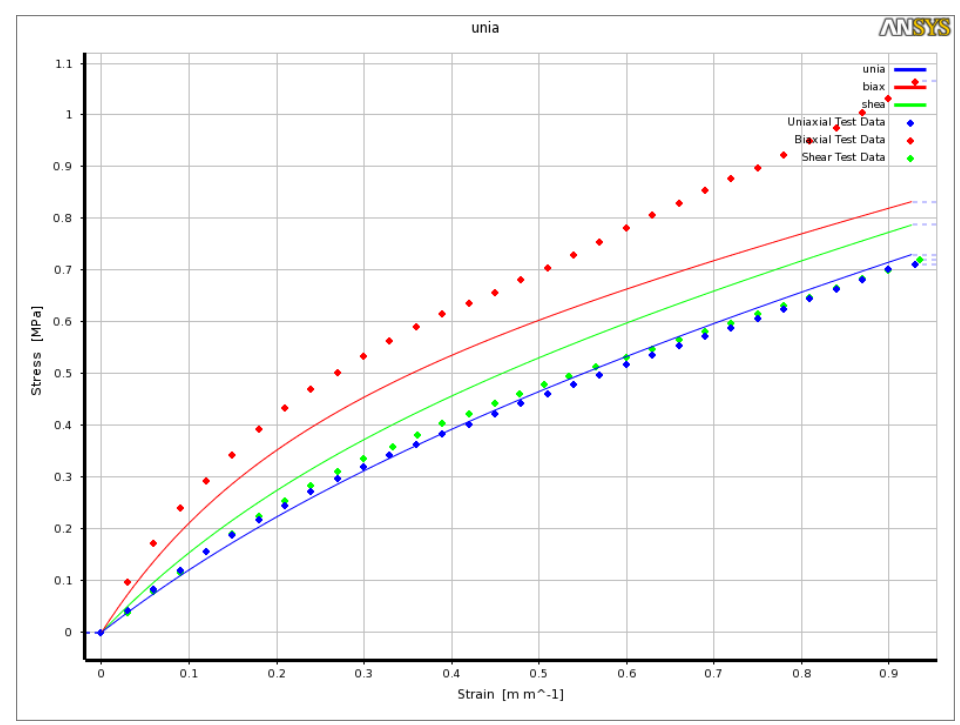

Figure 17. Curve fitting of Neo-Hookean model 


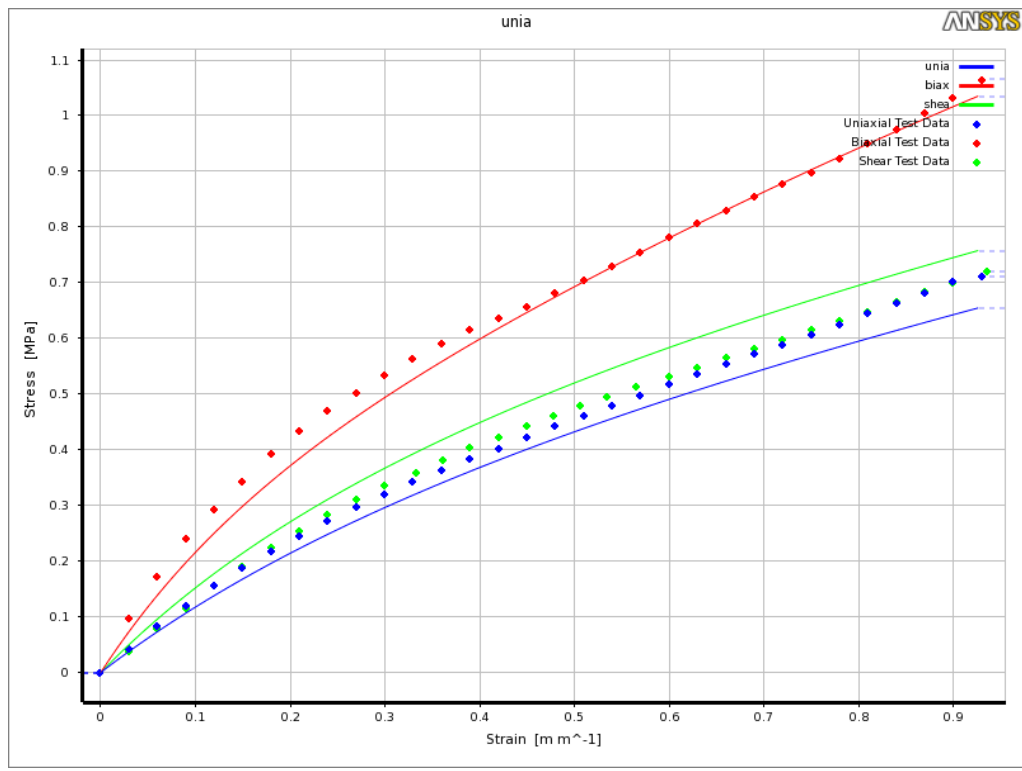

Figure 18. Curve fitting of Mooney-Rivlin model

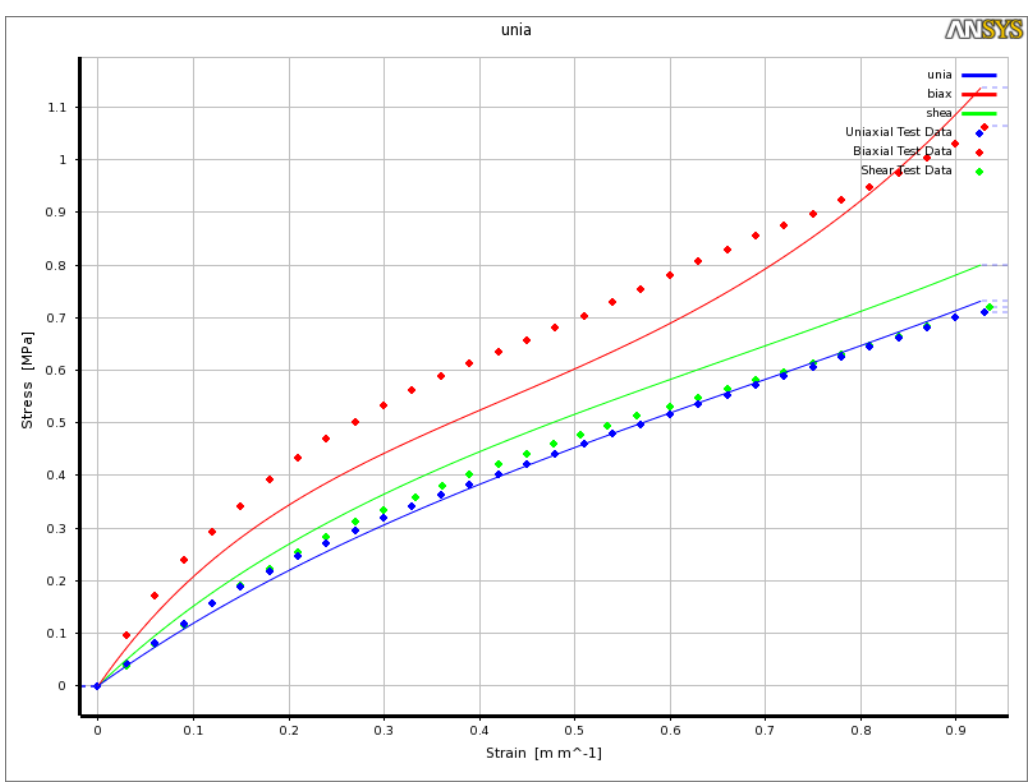

Figure 19. Curve fitting of Yeoh model

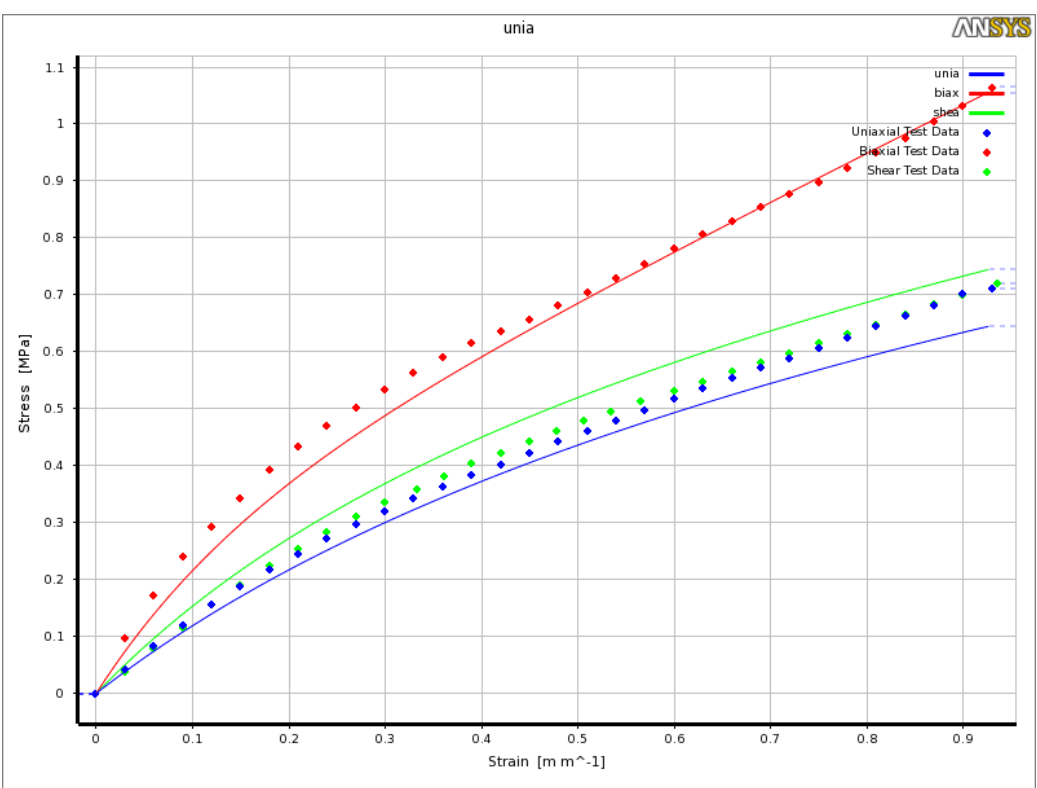

Figure 20. Curve fitting of Ogden model 


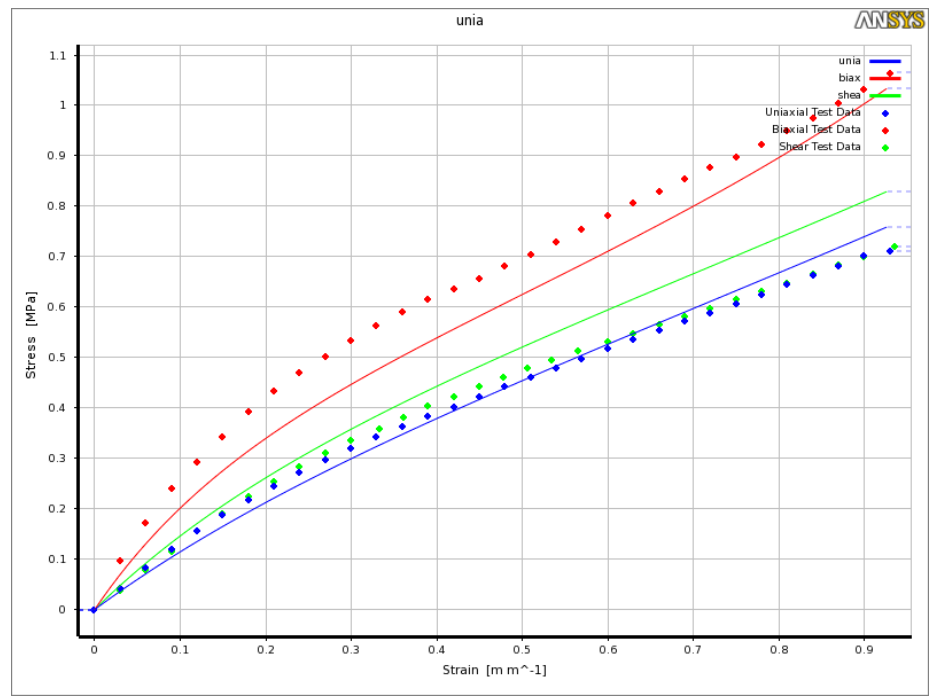

Figure 21. Curve fitting of Arruda-Boyce model

\section{Finite Element Analysis (FEA)}

A series FEA has been carried out by modeling all the experimental test setups, i.e. the uniaxial tensile, the planar shear, the equibiaxial tensile, and the volumetric test setups, of the low grade rubber with ANSYS, a commercially available general purpose finite element program. The loading conditions of the FEA are somewhat different with those of the experimental tests which apply the cyclic loadings, whereas the typical loadings employed in the FEA are the monotonic loadings. In the FEA, all the dimensions and loading condition of models are similar to those in the experimental tests. It is carried out to derive the actual behavior of the low grade rubber. All the experimental tests were then compared with the FEA results from five different constitutive models of a nearly incompressible hyperelastic material (low-grade rubber) to observe the most fitted curve against that experimental data.

\subsection{FE Model for Uniaxial Tension}

The specimen model was grip fixed at one end and kept freely at the other end in the longitudinal direction to simulate the actual pure tension behavior of rubber material. The deformation state of the FE model under the pure uniaxial tension is shown in Figure 22. The stress-strain data of each model under uniaxial tension obtained from the analysis is plotted and compared with the experimental data as shown in Figure 23.

Table 1. Coefficients for material constitutive models

\begin{tabular}{|c|c|c|}
\hline & Value & Unit \\
\hline \multicolumn{3}{|l|}{ 1. Neo-Hookean } \\
\hline$\mu_{0}$ & 0.44092 & $\mathrm{MPa}$ \\
\hline $\mathrm{D}_{1}$ & 0.00064512 & $\mathrm{MPa}^{-1}$ \\
\hline \multicolumn{3}{|c|}{ 2. Mooney-Rivlin (N = 3) } \\
\hline $\mathrm{C}_{10}$ & 0.18186 & $\mathrm{MPa}$ \\
\hline $\mathrm{C}_{01}$ & 0.036242 & MPa \\
\hline $\mathrm{C}_{11}$ & -0.0015086 & Mpa \\
\hline $\mathrm{D}_{1}$ & 0.00064512 & $\mathrm{MPa}^{-1}$ \\
\hline \multicolumn{3}{|l|}{ 3. $\operatorname{Yeoh}(\mathbf{N}=3)$} \\
\hline $\mathrm{C}_{10}$ & 0.21777 & $\mathrm{MPa}$ \\
\hline $\mathrm{C}_{20}$ & -0.0044601 & MPa \\
\hline $\mathrm{C}_{30}$ & 0.0020408 & $\mathrm{MPa}$ \\
\hline $\mathrm{D}_{1}$ & 0.00068928 & $\mathrm{MPa}^{-1}$ \\
\hline $\mathrm{D}_{2}$ & $6.5679 \mathrm{E}-05$ & $\mathrm{MPa}^{-1}$ \\
\hline $\mathrm{D}_{3}$ & $6.503 \mathrm{E}-07$ & $\mathrm{MPa}^{-1}$ \\
\hline \multicolumn{3}{|l|}{ 4. Ogden $(N=3)$} \\
\hline$\mu_{1}$ & -2597.9 & $\mathrm{MPa}$ \\
\hline$\mu_{2}$ & 913.83 & MPa \\
\hline$\mu_{3}$ & 4709.8 & MPa \\
\hline$\alpha_{1}$ & 0.12947 & \\
\hline$\alpha_{2}$ & 0.21024 & \\
\hline$\alpha_{3}$ & 0.030812 & \\
\hline $\mathrm{D}_{1}$ & 0.00068928 & $\mathrm{MPa}^{-1}$ \\
\hline $\mathrm{D}_{2}$ & $6.5679 \mathrm{E}-05$ & $\mathrm{MPa}^{-1}$ \\
\hline $\mathrm{D}_{3}$ & $6.503 \mathrm{E}-07$ & $\mathrm{MPa}^{-1}$ \\
\hline \multicolumn{3}{|l|}{ 5. Arruda-Boyce } \\
\hline$\mu_{0}$ & 0.36795 & MPa \\
\hline$\lambda_{\mathrm{m}}$ & 2.3191 & \\
\hline $\mathrm{D}_{1}$ & 0.00065821 & $\mathrm{MPa}^{-1}$ \\
\hline
\end{tabular}


However, the results illustrated in Figure 23. are not sufficient to decide which appropriate material model should be selected for representing the actual rubber behavior. A representative model must also be able to perform consistently for the other deformation states. Therefore, the FEA must be carried out further for the planar shear, the equibiaxial tensile, and the volumetric tests.

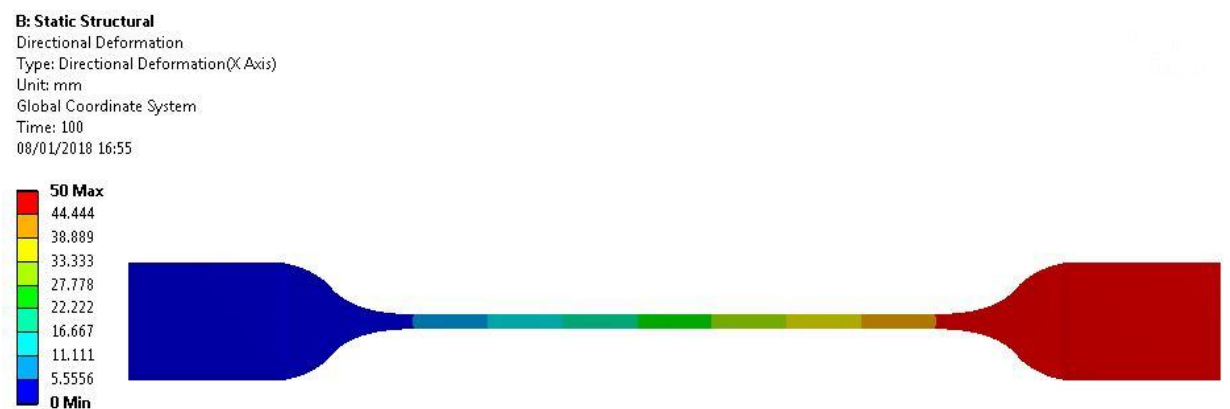

Figure 22. Deformation state of uniaxial tensile FE model

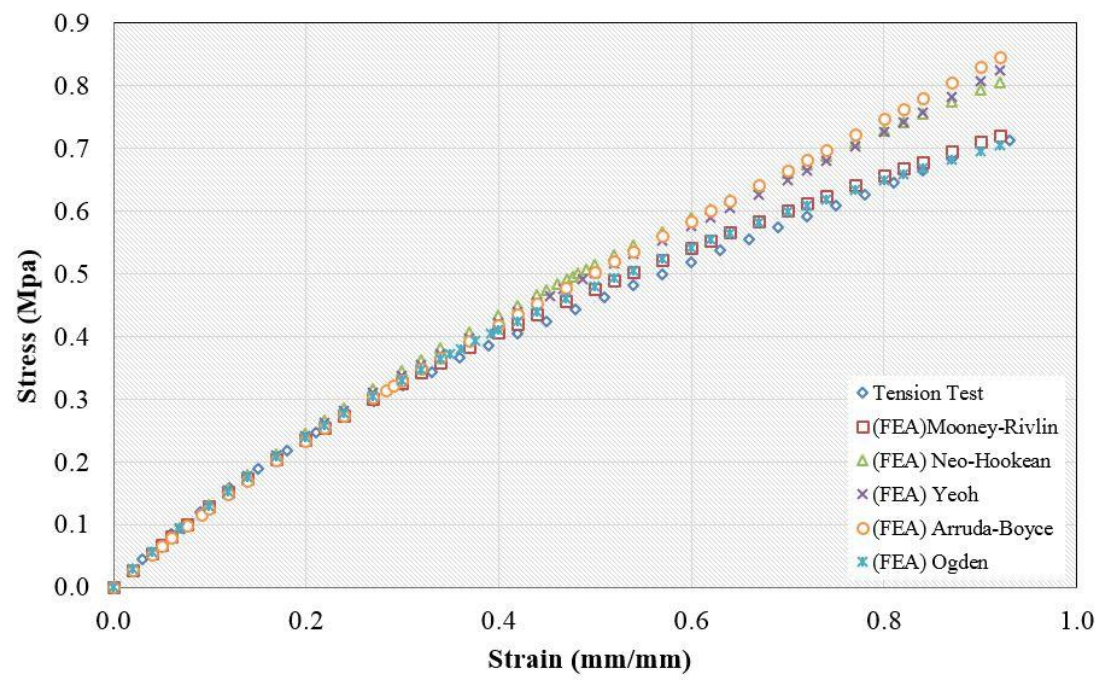

Figure 23. Data fitting of various hyperelastic models under uniaxial tension

\subsection{FE Model for Planar Shear}

Similar to the uniaxial tension, the specimen model was also grip fixed at one end and kept freely at the other end yet in the lateral direction to simulate the actual planar shear behavior of rubber material. The deformation state of the FE model under pure planar shear is shown in Figure 24. The stress-strain data of each model under planar shear obtained from the analysis is plotted and compared with the experimental data as shown in Figure 25.

As shown in Figure 25, the experimental data is denoted with the red dots. Although the curve fitting results are not as good as those of the uniaxial tension, both Mooney-Rivlin and Ogden models are still found in good agreements with the experimental data compared to those obtained from the remaining models. From the first two FE models (the uniaxial tension and the planar shear models), it can be concluded that both Mooney-Rivlin and Ogden models are very promising to be selected as one of the proper SEFs for rubber material than the other models. The next FE model (the equibiaxial tension model) will confirm which one of these models is more accurate in representing the actual behavior of rubber material in the FEA.

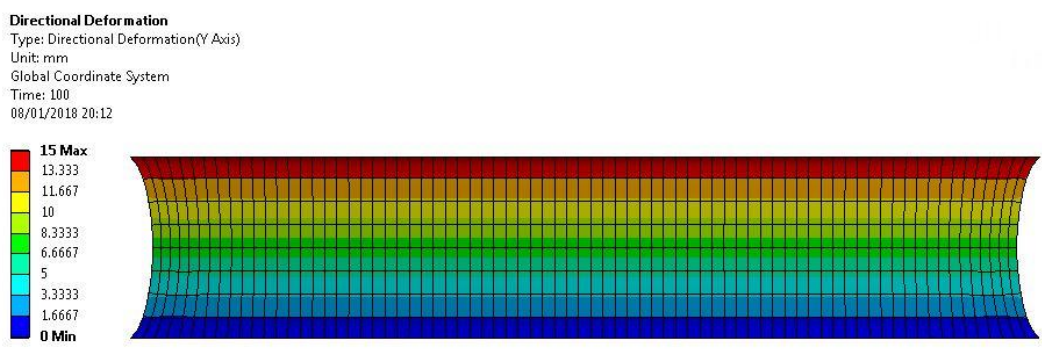

Figure 24. Deformation state of planar shear FE model 


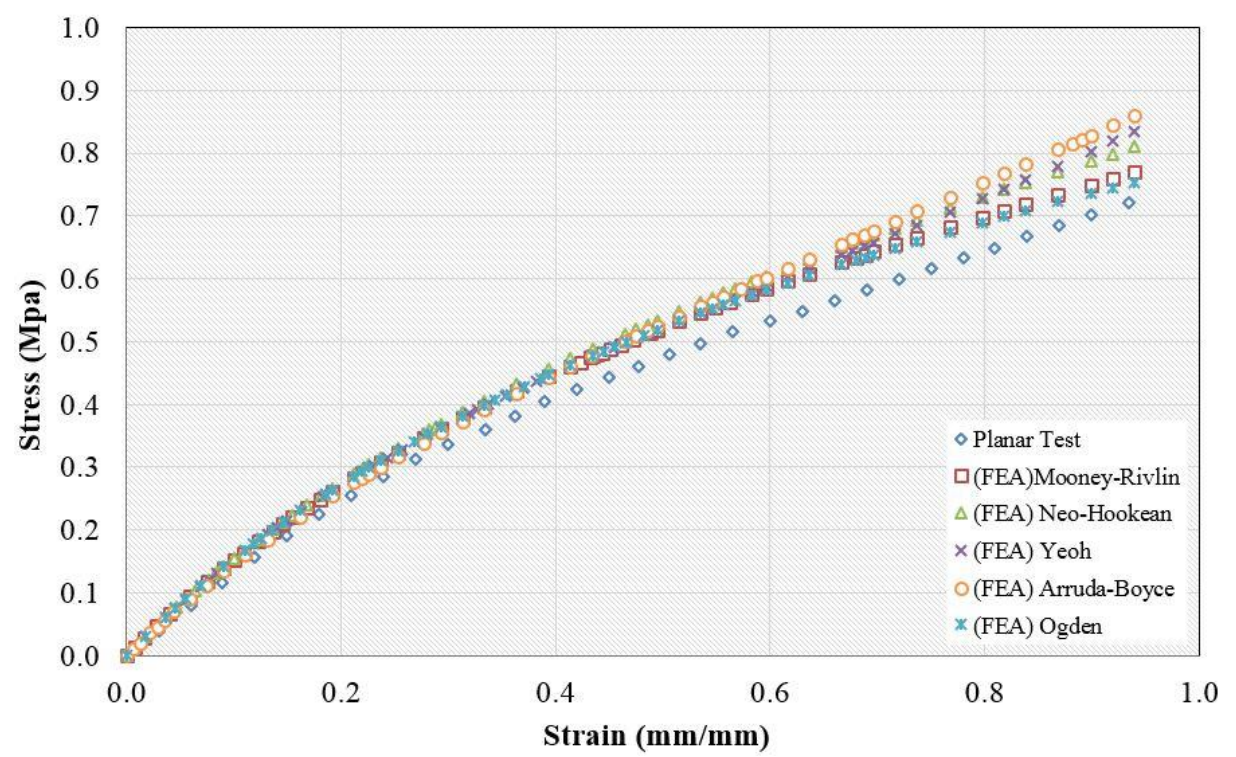

Figure 25. Data fitting of various hyperelastic models under planar shear

\subsection{FE Model for Equibiaxial Tension}

The FE modeling of the specimen under equibiaxial tension is intended to simulate the actual pure radial strain behavior of rubber material. The model has sixteen "clamps" which were pulled simultaneously up to the desired strain level in the radial direction, thus, it enables the model to experience the pure radial stretching.

The deformation state of the equibiaxial model is considerably different than that in either the uniaxial tension or the planar shear. Since the clamp edges of the model were subjected to tension in the radial direction, the displacement at the clamps were different than that in the effective area, particularly within the gage length. This is due to the stiffer effective area than the clamps edges. It means that in order to achieve 100 percent strain level, the clamp edges must be pulled more than $12.5 \mathrm{~mm}$. It is considerably difficult to make sure how much the displacement must be subjected to the clamp edges to derive a particular strain level in the effective area. Thus, a trial and error is conducted to derive the desired strain level by FEA.

In the FEA, the maximum strain level of equibiaxial tension is selected to be approximately 20 percent of the effective gage length, or in other words, the maximum strain is set to be 0.2 . It means that the total gage length will be $30 \mathrm{~mm}$ (5-mm increase from its initial length). Actually, the maximum strain level of 20 percent is due to the prediction of rubber strain in the radial direction of the BI that will not exceed 20 percent. By trial and error, in order to achieve 20 percent strain level, the clamps must be pulled approximately $8.3 \mathrm{~mm}$ from their initial positions in the radial direction. The deformation state of the FE model under pure strain in the radial direction is shown in Figure 26.

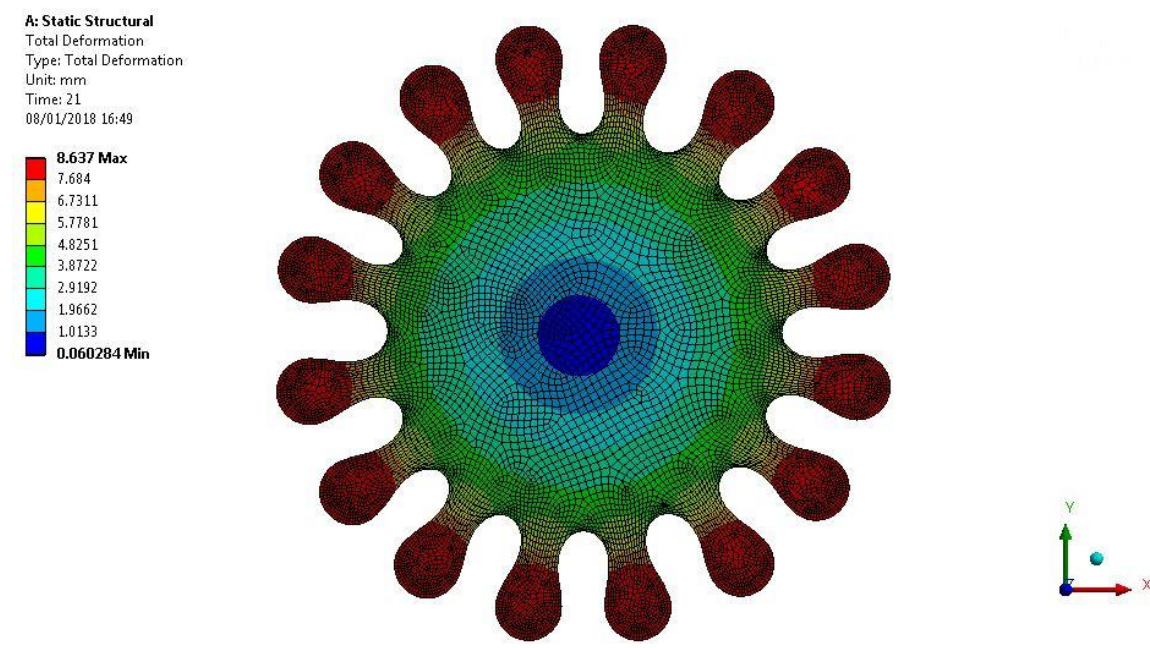

Figure 26. Deformation state of equibiaxial tensile FE model 


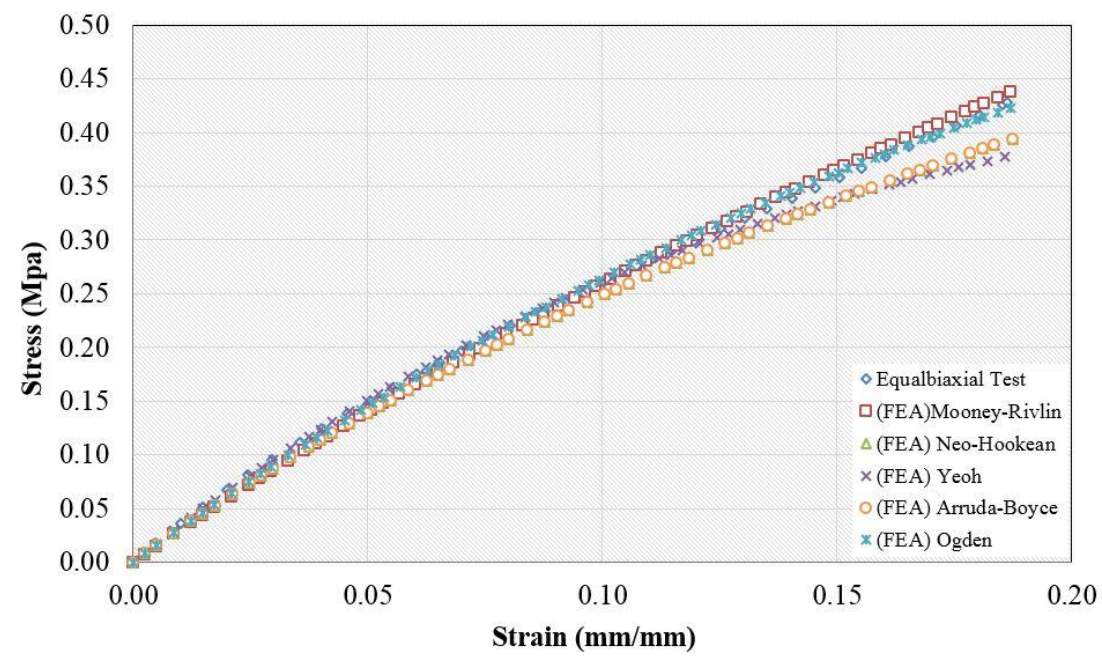

Figure 27. Data fitting of various hyperelastic models under equibiaxial tension

The stress-strain data of each model under equibiaxial tension obtained from the analysis is plotted and compared with the experimental data as shown in Figure 27. It can also be seen in the figure that the phenomenon found in the uniaxial tension and planar shear is also similarly found in the equibiaxial tension case. Both Mooney-Rivlin and Ogden models can consistently perform good fits, starting at zero strain until maximum strain, as compared to the experimental data.

\subsection{FE Model for Volumetric Compression}

The boundary conditions of the specimen model are arranged such a way that it will undergo the pure compression in order to observe its nearly incompressible behavior. Fixed and lateral constraints were applied at the respective bottom and body to assure that the movement only in the longitudinal direction under pure compression. The relationships between the force and the deformation were captured during the simulation for computing the volumetric stress-volumetric change data. The stress in the volumetric compressive test is a hydrostatic pressure.

The deformation state of FE volumetric model under pure compression in longitudinal direction is shown in Figure 28. The model was compressed until it deformed about $2 \mathrm{~mm}$. The hyperelastic constitutive models were used to describe the material properties of the models. The relationships between the volumetric stress and the volumetric change ratio, for each model, are plotted and compared with the experimental data as shown in Figure 29. The initial slope of the resulting volumetric stress-volumetric change ratio is the bulk modulus. The value is typically two to three orders of magnitude greater than the shear modulus for elastomer. In this part of verification, the difference in behavior is clearly exhibited by both Mooney-Rivlin and Ogden models that in the three previous tests, they always performed similar characteristics. In Figure 29, it is clear now in this volumetric compressive test that the MooneyRivlin model is not able to maintain its good fitting to the experimental result under pure compression in the longitudinal direction. However, the Ogden model shows a consistent approach in representing the actual behavior of the rubber material throughout its overall deformation state.
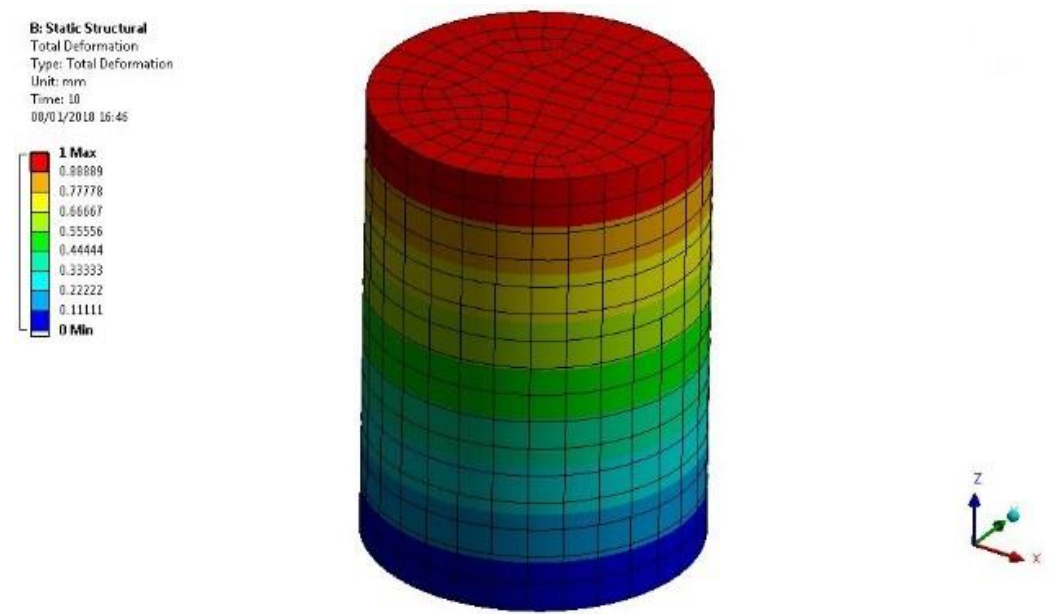

Figure 28. Deformation state of volumetric compressive FE model 


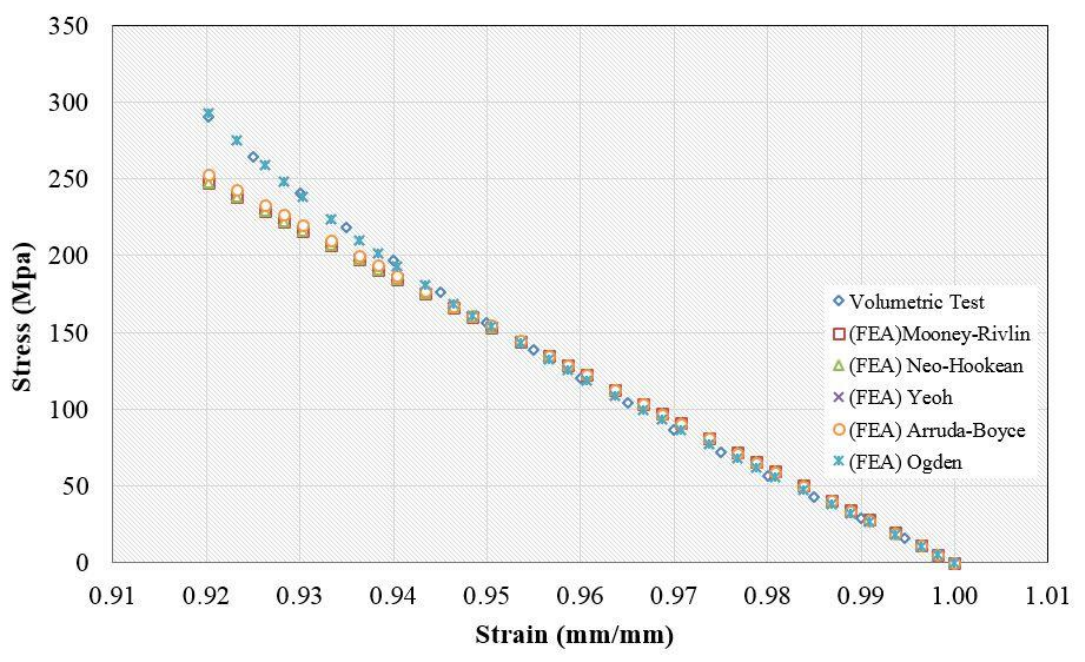

Figure 29. Data fitting of various hyperelastic models under volumetric compression

\section{Experimental Validation}

The goal of this section is to verify the validity of the Ogden model coefficient derived from the FE curve fitting process. A series of FEA on a circular elastomeric bearing was conducted using a general-purpose finite element program, ANSYS. The validation process was typically carried out by many researchers through the validation of the FE results with the experimental data [23]. To validate the Ogden model coefficient, the FEA of a low-cost rubber base isolator (LCRBI) was performed to predict the force and displacement of the LCRBI from the experimental test [42].

In order to obtain the experimental data, a BI test was performed under vertical pure compression load. The data pairs of force-displacement were recorded during the test to present the experimental data curve. The proposed LCRBI used the thin perforated steel plates instead of the regular solid ones which were embedded in the rubber as reinforcement. The embedded perforated steel plates in the rubber is intended to reduce the weight of the required steel reinforcement, resulting in the reduction of the overall weight of the LCRBI. This is due to the low gravity and seismic loads of the one- or two-story housings that they will support in their actual application. In the case, the perforated steel plates with circular openings arranged in a standard 60-degree triangular pattern were embedded in alternate layers with the rubber as reinforcement of LCRBI. The standard 60-degree staggered formation is the most popular opening arrangement due to its inherent strength and the large opening area it provides [42]. The BI was reinforced with nineteen layers of perforated steel plates with the opening area percentage of approximately 51 percent of the overall area, as shown in Figure 30. The details of the BI specimen and the test setup are shown in Figure 31. and Table 2. The testing procedure complies with BS-EN 1337-2005. The BI was subjected to an axial load of about 40 $\mathrm{kN}$ with a loading rate of $5.0 \pm 0.5 \mathrm{MPa} / \mathrm{min}$.

In modeling the LCRBI with FE, each layer of reinforcement was made up of a thin perforated steel plate with a specific opening area percentage. Since the running process was time consuming, the LCRBI was modeled in a quarter from the overall LCRBI model as shown in Figure 32. In order to generate a quarter model as shown in Figure 32, it was arranged symmetrically in both $x-z$ and $y-z$ planes. The symmetries in both $x-z$ and $y-z$ planes produced the free translations of the model in the $\mathrm{x}$ - and z-directions as well as in the $\mathrm{y}$ - and $\mathrm{z}$-directions, respectively. In the ANSYS element library, SOLID186, 20-node layered structural solid elements, were used to model the perforated steel plates, the rubber, and the top and bottom side steel plates. This element has three translation degrees of freedom (DOF) at each node along $\mathrm{x}-, \mathrm{y}-$, and $\mathrm{z}$-directions. The meshing conditions in the model take into account the mesh quality and the time consumed for the running process. Therefore, the mesh sizes were set 2,5 , and $5 \mathrm{~mm}$ for the perforated steel plates, the rubber layers, and the end steel plates, respectively.

The modeling was performed using 3D surface-to-surface contact elements, CONTA174 and TARGE170. Bounded contact surface was also used to model the contact surface between layers. Contact elements are nonlinear elements and their numerical solution requires lot of computational power.

Finally, the LCRBI specimen was also simulated by FEA. Hexahedron element type was adopted for LCRBI modeling. A boundary condition at the bottom side was specified as a fixed base (fixed in all directions) while the top side of the end steel plate was free in z-direction and fixed in both $x$ - and y-directions. The loading condition was applied as a pressure load on the top side of LCRBI. The finite element program used employs the Newton-Raphson method to solve the nonlinear problem. The load is subdivided into a series of load increments that can be applied over several load steps. 
Figure 33. shows the deformation state of LCRBI under vertical compressive loading. The overall vertical deformation was approximately $2.5 \mathrm{~mm}$. Figure 34. graphically depicts the closeness of the FE approximations to the experimental force-displacement data. The percentage of relative error between the experimental data and FE results is derived by averaging the RMS error expressed in Equation 19 [23]. The error was found to be 4.373 percent for the LCRBI model under compression load.

$R M S_{\text {avg }}$ Error $=\frac{1}{N} \sqrt{\sum_{i=1}^{N}\left(\frac{F_{\exp }-F_{F E}}{F_{\exp }}\right)}$

Where $N$ is the number of data point calculated by FEA. $F_{\text {exp }}, F_{F E}$ are the experimental and the finite element forces, respectively. It exhibits that the Ogden model works well for predicting the behavior of LCRBI model under compression load.

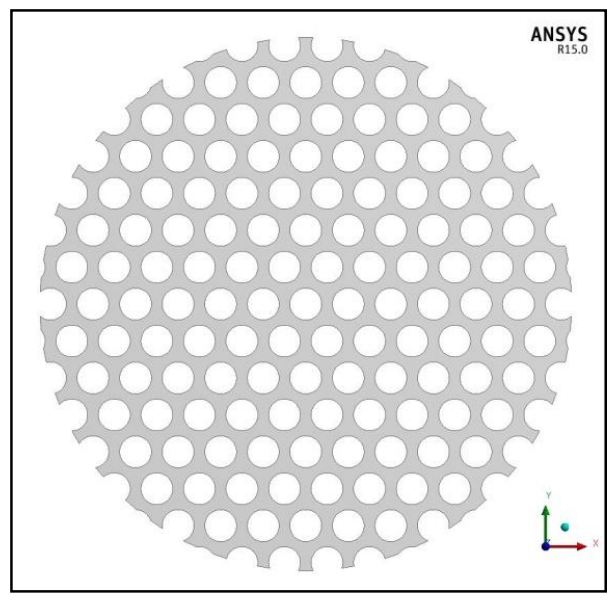

Figure 30. Full model of a perforated steel plate

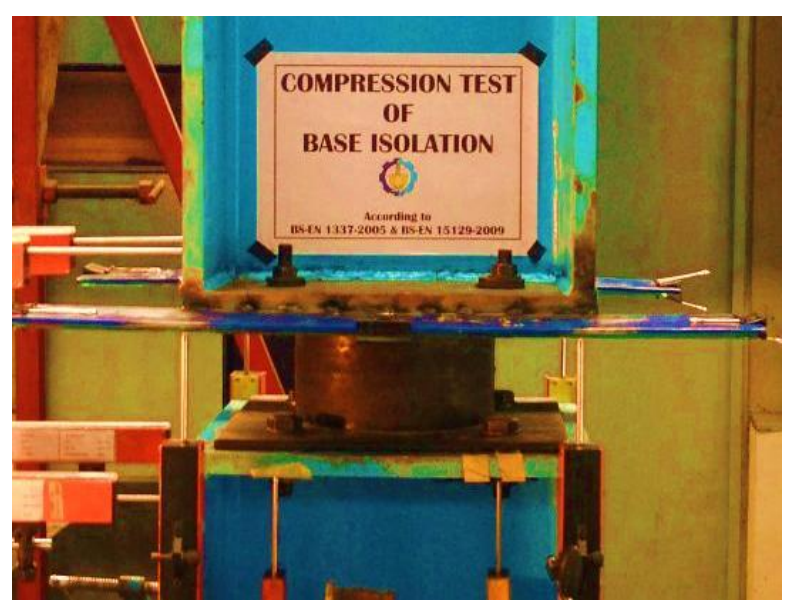

Figure 31. LCRBI specimen under vertical pure compressive test

Table 2. Details of LCRBI specimen

\begin{tabular}{ll}
\hline Circular Isolator & Value \\
\hline Diameter & $200 \mathrm{~mm}$ \\
Total height & $139 \mathrm{~mm}$ \\
Thickness of perforated plate & $1 \mathrm{~mm}$ \\
Number of perforated plate & 19 \\
Percentage open area & $51 \%$ \\
Opening diameter & $12 \mathrm{~mm}$ \\
Pitch & $16 \mathrm{~mm}$ \\
Thickness of rubber layer & $5 \mathrm{~mm}$ \\
Number of rubber layer & $20 \mathrm{~mm}$ \\
Thickness of 2 end plate & $10 \mathrm{~mm}$ \\
\hline
\end{tabular}




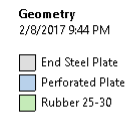

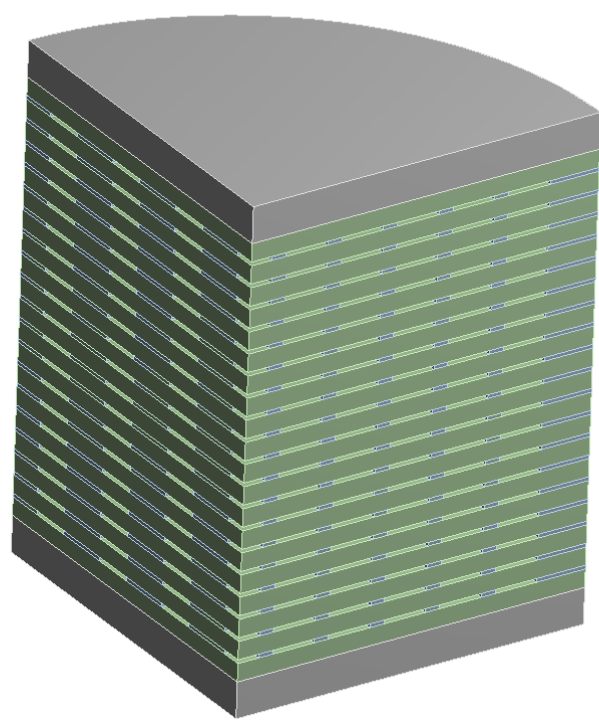

ANSYS

Figure 32. A quarter FE modeling of LCRBI
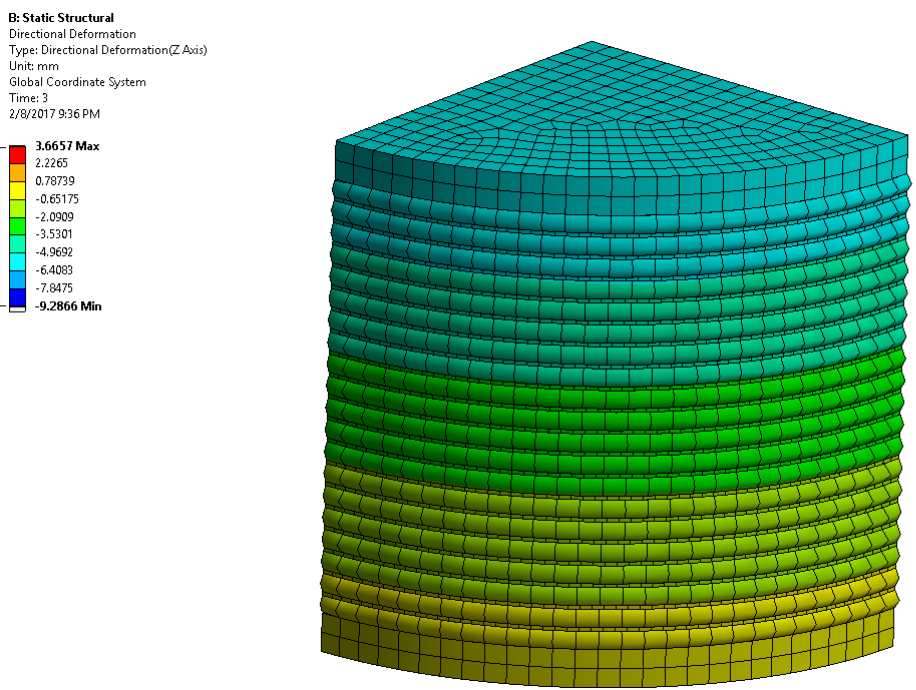

ANSYS

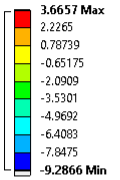

Figure 33. Stress contour of FE modeling of LCRBI under vertical compressive loading

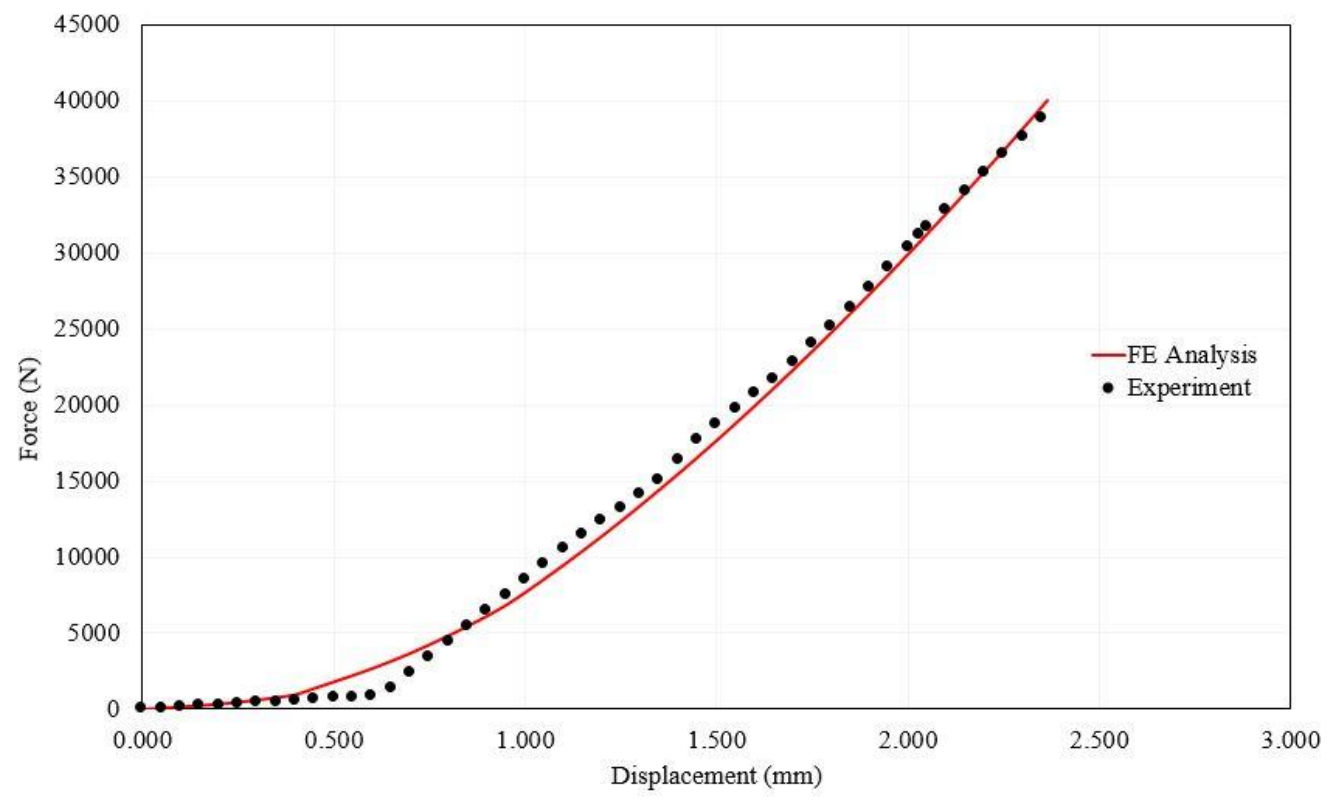

Figure 34. Comparison between FE prediction and experimental data of LCRBI 


\section{Conclusions}

A series of FEA was carried out to predict a proper SEF of low-grade rubber material with an average hardness value of 47.2. The FEA was conducted due to the insufficient curve fitting process with the experimental data in simulating the actual hyperelastic material behavior. In the first three FE simulations (the uniaxial tensile, the planar shear, and the equibiaxial tensile tests), both Mooney-Rivlin and Ogden models exhibited a similar characteristic in describing the rubber material behavior. In other words, if the FE approach is only applied to analyze the hyperelastic material, such as rubber, without its compressible effect, they both are very promising to be adopted as SEFs for illustrating the mechanical characteristic of the rubber. However, in the volumetric simulation, the Mooney-Rivlin model is not capable of accounting for the compressible effect of the hyperelastic material, while the Ogden model consistently shows a very good agreement with the experimental data throughout the overall deformation states.

To validate the applicability of the Ogden model, a vertical compressive test of a LCRBI was conducted in order to verify the selected constitutive models in representing the actual hyperelastic behavior of a specified rubber material. From the discussion above, the following conclusions can be drawn:

1. In order to obtain an appropriate constitutive model of nearly incompressible material such as low grade rubber, all of the required laboratory tests, i.e. the uniaxial tensile, the planar shear, the equibiaxial tensile, and the volumetric compressive tests should be performed. This is to ensure the consistency of the selected model in the analysis of LCRBI under various loading stages.

2. Although the Mooney-Rivlin model when implemented in the FEA exhibits reasonably good agreement with the experimental data in describing the actual uniaxial tensile, the planar shear, and the equibiaxial compressive behaviors of hyperelastic material, it is still not enough to claim that the Mooney-Rivlin model is suitable for SEF of hyperelastic material due to its inconsistency in modeling its actual volumetric behavior. In other word, to obtain a proper SEF, the selected model must be able to predict accurately the results from the overall experimental tests, e.g. the Ogden model.

3. The Ogden model consistently performs a quite accurate prediction in terms of stress-strain relationship when implemented in the FE model for predicting the behavior of BI under concentric axial compression. The result indicates that the selected model performs an accurate prediction compared with the experimental data.

4. As a recommendation, the adoption of several models proposed by other researchers in FEA for representing various mechanical behaviors of hyperelastic material such as rubber is acceptable when the test data for developing the curve fitting process is not sufficient to describe the actual constitutive behaviors of hyperelastic material.

\section{Acknowledgements}

The authors would like to thank the Axel Product, Inc., Ann Arbor, Michigan, USA for their generous supports in providing their laboratory facilities to make possible all the rubber's mechanical property tests. The authors also would like to thank the R \& D Center of Settlement, Ministry of Public Works and Housing, Cileunyi, Bandung, for all the experimental facilities and supports provided.

\section{Funding}

This study is part of a research project, entitled "Development of Low-Cost Base Isolation for Residential Houses in Highly Seismic Regions," which was funded by the Ministry of Research and Higher Education, Indonesia via the Program of the Excellent Research of College (PUPT), contract number 003246.191/IT2.11/PN.08/2015.

\section{References}

[1] Habieb, A. B.; G. Milani; Tavio; and F. Milani. "Seismic Performance of A Masonry Building Isolated with Low Cost Rubber Isolators," WIT Transactions on The Built Environment, WIT Press, V. 172, 2017, doi.org/10.2495/eres170071.

[2] Habieb, A. B.; G. Milani; Tavio; and F. Milani. "Numerical Model of Low Cost Rubber Isolators for Masonry Housing in High Seismic Regions," International Journal of Civil, Environmental, Structural, Construction and Architectural Engineering, World Academy of Science, Engineering and Technology, V. 11, No. 5, 2017, pp. 647-653.

[3] Habieb, A. B.; G. Milani; Tavio; and F. Milani. "Low Cost Frictional Seismic Base-Isolation of Residential New Masonry Buildings in Developing Countries: A Small Masonry House Case Study,” The Open Civil Engineering Journal, V. 11, No. Suppl-5, M2, 29 Dec. 2017, doi.org/10.2174/1874149501711011026.

[4] Habieb, A. B.; G. Milani; Tavio; and F. Milani. "A Low Cost Rubber Seismic Isolation System for New Masonry Residential Buildings in Developing Countries,” AIP Conference Proceedings, V. 1906, No. 090012, 28 Nov. 2017, doi.org/10.1063/1.5012369.

[5] Sugihardjo, H.; Tavio; and Y. Lesmana. "Behavior of a Base-Isolated Residential House in a Highly Seismic Region," 
International Journal of Applied Engineering Research (IJAER), Research India Publications, V. 11, No. 14, 2016, pp. 8253-8258.

[6] Tavio; H. Sugihardjo; and Y. Lesmana. "Seismic Behavior of Base-Isolated Residential House with Various Soil Type in High Seismic Regions by Nonlinear Time-History Analysis," The 3rd International Conference on Earthquake Engineering and Disaster Mitigation 2016 (ICEEDM-III 2016): Advancing Science and Technology for Preparedness and Mitigation of Earthquake Disasters, Ayodya Hotel, Nusa Dua, Bali, Indonesia, 1-2 Aug. 2016.

[7] Lesmana, Y.; Tavio; and H. Sugihardjo. "Finite Element Analysis of Perforated-Reinforced Elastomeric Isolators (PREIs) under Pure Lateral Loading," The 3rd International Conference on Earthquake Engineering and Disaster Mitigation 2016 (ICEEDM-III 2016): Advancing Science and Technology for Preparedness and Mitigation of Earthquake Disasters, Ayodya Hotel, Nusa Dua, Bali, Indonesia, 1-2 Aug. 2016.

[8] Mansouri, I.; G. G. Amiri, J. W. Hu, M. Khoshkalam, S. Soori, and S. Shahbazi. "Seismic Fragility Estimates of LRB Base Isolated Frames using Performance-Based Design.” Shock and Vibration (2017): 20 pp. doi.org/10.1155/2017/5184790.

[9] Kaloop, M. R., and J. W. Hu. "Seismic Response Prediction of Buildings with Base Isolation using Advanced Soft Computing Approaches," Advances in Materials Science and Engineering. (2017): 12 pp. doi.org/10.1155/2017/7942782.

[10] Li, Y., and Q. Wu. "Experimental Study on Friction Sliding Performance of Rubber Bearings in Bridges." Advances in Materials Science and Engineering (2017): 8 pp. doi.org/10.1155/2017/5845149.

[11] Sasso, M., G. Palmieri, G. Chiappini, and D. Amodio. "Characterization of Hyperelastic Rubber-Like Materials by Biaxial and Uniaxial Stretching Test Based on Optical Methods.” Polymer Testing (V. 27 2008): 995-1004. doi.org/10.1016/j.polymertesting.2008.09.001.

[12] Avanzini, A., and D. Battini. "Integrated Experimental and Numerical Comparison of Different Approaches for Planar Biaxial Testing of a Hyperelastic Material.” Advances in Materials Science and Engineering, Hindawi (Article ID 6014129, 2016): 12 pp. http://dx.doi.org/10.1155/2016/6014129.

[13] Guo, Z., and L. J. Sluys. "Application of A New Constitutive Model for the Description of Rubber-Like Materials under Monotonic Loading.” International Journal of Solids and Structures. (V. 43 2006): 2799-2819. doi.org/10.1016/j.ijsolstr.2005.06.026.

[14] Guelon, T., E. Toussaint, J. B. Le Cam, N. Promma, and M. Grediac. “A New Characterization Method for Rubber.” Polymer Testing (V. 28 2009): 715-723. doi.org/10.1016/j.polymertesting.2009.06.001.

[15] Kaliske, M., L. Nasdala, and H. Rothert. "On Damage Modeling for Elastic and Viscoelastic Materials at Large Strain." Computers and Structures (V. 79 2001): 2133-2141. doi.org/10.1016/s0045-7949(01)00061-X.

[16] Humphrey, J. D., and F. C. P. Yin. "On Constitutive Relations and Finite Deformations of Passive Cardiac Tissue I: A Pseudo Strain Energy Function.” ASME Journal of Biomechanical Engineering (V. 109 1987): 298-304. doi.org/10.1115/1.3138684.

[17] Humphrey, J. D. "Continuum Biomechanics of Soft Biological Tissues." Proceeding of the Royal Society London A (V. 59, 2003): 1-44. doi.org/10.1098/rspa.2002.1060.

[18] Sussman, T., and K. J. Bathe. "A Model of Incompressible Isotropic Hyperelastic Material Behavior using Spline Interpolations of Tension- Compression Test Data." Communications in Numerical Methods in Engineering. (V. 25 2009): $53-63$. doi.org/10.1002/cnm.1105.

[19] Miller, K. “Testing Elastomer for Hyperelastic Material Models in Finite Element Analysis." Axel Products Testing and Analysis Report (2000).

[20] Khajehsaeid H., K. Arghavani, and R. Naghdabadi. "A Hyperelastic Constitutive Model for Rubber-Like Materials." European Journal of Mechanics, A Solids. (V. 38 2013): 144-151. doi.org/10.1016/j.euromechsol.2012.09.010.

[21] Chagnon, G., G. Marckmann, and E. Verron. "A Comparison of the Hart-Smith Model with Arruda-Boyce and Gent Formulations for Rubber Elasticity.” Rubber Chemistry and Technology. (V. 77 No. 4 2004): 724-735.

[22] Ali, A., M. Hosseini, and B. B. Sahari. “A Review of Constitutive Models for Rubber-Like Materials.” American Journal of Engineering and Applied Sciences, 2010. (V. 3 No. 1 2010): 232-239. doi.org/10.3844/ajeassp.2010.232.239.

[23] Shahzad, M., A. Kamran, M. Z. Siddiqui, and M. Farhan. "Mechanical Characterization and FE Modelling of a Hyperelastic Material.” Materials Research (V. 18 No. 5 2015): 918-924. doi.org/10.1590/1516-1439.320414.

[24] Charlton, D. J., J. Yang, and K.K. Teh. "A Review of Methods to Characterize Rubber Elastic Behaviour for Use in Finite Element Analysis.” Rubber Chemistry and Technology (V. 67 No. 3 1993): 481 - 502. doi.org/10.5254/1.3538686.

[25] Yeoh O. H. "Some benchmark problems for FEA from torsional behaviour of rubber." Rubber Chemistry and Technology (V. 76 No. 5 2003): 1212-1217. doi.org/10.5254/1.3547798. 
[26] Mohan, C.V.R., J. Ramanathan, S. Kumar, and A. V. S. K. S. Gupta. "Characterisation of materials used in flex bearings of large solid rocket motors.” Defence Science Journal (V. 61 No. 3 2011): 264-269. doi.org/10.14429/dsj.61.52.

[27] Hosseinzadeh, M., M. Ghoreishi, and K. Narooei. "Investigation of Hyperelastic Models for Nonlinear Elastic Behavior of Demineralized and Deproteinized Bovine Cortical Femur Bone." Biomedical Materials (V. 59 2016): $393-403$. doi.org/10.1016/j.jmbbm.2016.02.027.

[28] Ogden, R. W. "Non-linear Elastic Deformations.” Dover Publications, New York (1997): 560 pp. doi.org/10.1016/0264682x(84)90061-3.

[29] Timbrell C., M. Wiehahn, G. Cook, and A. H. Muhr. "Simulation of Crack Propagation in Rubber." in Constitutive Models for Rubber III, edited by Busfield, J., and Muhr, A., A Balkema Publishers, UK (2003): 11-20.

[30] Mooney, M. “A Theory of Large Elastic Deformation.” Journal of Applied Physics (V. 11 No. 9, 1940): 582-592. doi.org/10.1063/1.1712836.

[31] Rivlin, R. S. "Large Elastic Deformations of Isotropic Materials IV: Further Developments of the General Theory." Philosophical Transactions of the Royal Society A, (V. 241 No. 835 1948): 379-397. doi.org/10.1098/rsta.1948.0024.

[32] Bol, M., and S. Reese. "Finite Element Modeling of Polymer Networks Based on Chain Statistics." in Constitutive Models for Rubber III, edited by Busfield, J.; and Muhr, A., A Balkema Publishers, UK (2003): 203-211.

[33] Yeoh, O. H. "Some Forms of the Strain Energy Function for Rubber." Rubber Chemistry and Technology (V. 66, No. 5 1993): 754-771. doi.org/10.5254/1.3538343.

[34] Gent, A. N. “A New Constitutive Relation for Rubber.” Rubber Chemistry and Technology 1996 (V. 69 No. 11996 ): $59-61$. doi.org/10.5254/1.3538357.

[35] Ghosh, P., A. Saha, and R. Mukhopadhyay. "Prediction of Tyre Rolling Resistance using FEA." in Constitutive Models for Rubber III, edited by Busfield, J., and A. Muhr, A Balkema Publishers, UK (2003): 141-145.

[36] Ogden, R. W. "Large Deformation Isotropic Elasticity on the Correlation of Theory and Experiment for Incompressible Rubber-Like Solids.” Preceding of the Royal Society London A 326 (V. 1567 1972): 565-584. doi.org/10.1098/rspa.1972.0026.

[37] Arruda, E. M., and M. C. Boyce. "A Three-Dimensional Constitutive Model for the Large Stretch Behavior of Rubber Elastic Materials.” Journal of the Mechanics and Physics of Solids (V. 41 No. 2 1993): 389-412. doi.org/10.1016/0022-5096(93)90013-6.

[38] Seibert, D. J., and N. Schoche. "Direct Comparison of Some Recent Rubber Elasticity Models." Rubber Chemistry and Technology (V. 73 2000): 366-384.

[39] Moran, R., J. H. Smith, and J. J. Garcia. "Fitted Hyperelastic Parameters for Human Brain Tissue from Reported Tension, Compression, and Shear Tests." Journal of Biomechanics (V. 47 2014): 3762-3766. doi.org/10.1016/j.jbiomech.2014.09.030.

[40] Darijani, H., R. Naghdabadi, and M. Kargarnovin. "Hyperelastic Materials Modelling using a Strain Measure Consistent with the Strain Energy Postulates." Proceedings of the Institution of Mechanical Engineers, Part C: Journal of Mechanical Engineering Science (V. 224 2010): 591-602. doi.org/10.1243/09544062jmes1590.

[41] Ogden, R., G. Saccomandi, and I. Sgura. "Fitting Hyperelastic Models to Experimental Data." Computational Mechanics (V. 34 2004): 484-502. doi.org/10.1007/s00466-004-0593-y.

[42] O’Donell \& Associates, Inc. "Strength of Perforated Metal. In: Designers, Specifiers and Buyers Handbook for Perforated Metals." A Publication of the Industrial Perforators Association (1993): 12-15.

[43] Tavio; H. Sugihardjo; A. Purniawan; and Y. Lesmana. "Behavior of Rubber Base Isolator with Various Shape Factors.” AIP Conference Proceedings (2017): doi.org/10.1063/1.501151. 